\title{
A comprehensive investigation on the formation of organo-sulfur molecules in dark clouds via neutral-neutral reactions
}

\author{
M. Yamada ${ }^{1}$, Y. Osamura ${ }^{1}$, and R. I. Kaiser ${ }^{2, \star}$ \\ ${ }^{1}$ Department of Chemistry, Rikkyo University, 3-34-1 Nishi-ikebukuro, Tokyo 171-8501, Japan \\ 2 Department of Chemistry, University of York, YO10 5DD, UK
}

Received 11 June 2002 / Accepted 9 September 2002

\begin{abstract}
Fifteen reactions on the doublet $\mathrm{HC}_{n} \mathrm{~S}$ and singlet/triplet $\mathrm{H}_{2} \mathrm{C}_{n} \mathrm{~S}(n=1,2)$ potential energy surfaces have been investigated theoretically via electronic structure calculations to unravel the formation of hydrogen deficient, sulfur bearing molecules via bimolecular reactions of two neutral species in cold molecular clouds. Various barrierless reaction pathways to synthesize astronomically observed $\mathrm{C}_{n} \mathrm{~S}$ and hitherto undetected $\mathrm{HC}_{n} \mathrm{~S}(n=1,2)$ isomers are offered. These data present important guidance to search for rotational transitions of the elusive thioformyl $\mathrm{HCS}\left(\mathrm{X}^{2} \mathrm{~A}^{\prime}\right)$ and thioketenyl $\mathrm{HCCS}\left(\mathrm{X}^{2} \Pi\right)$ radicals in the interstellar medium.
\end{abstract}

Key words. astrochemistry - ISM: molecules - molecular processes - methods: miscellaneous

\section{Introduction}

Untangling the synthetic routes to form sulfur-carrying molecules in the interstellar medium is a significant instrument to understand the chemical evolution and physical conditions in star forming regions and in circumstellar envelopes (Minh \& van Dishoeck 2000). The chemistry of sulfur carrying species can also be used as a clock to elucidate the history of cold molecular clouds. Compared to the cosmic carbon versus sulfur ratio of 15:1 (Bakes 1997), sulfur is severely depleted in carbon containing molecules. So far, only carbonmonosulfide (CS), carbonylsulfide (COS), isothiocyanoacid (HNCS), thiomethanol $\left(\mathrm{CH}_{3} \mathrm{SH}\right)$, thioformaldehyde $\left(\mathrm{H}_{2} \mathrm{CS}\right)$, two ions $\mathrm{HCS}^{+}$and $\mathrm{CS}^{+}$, and the cummulenes $\mathrm{C}_{2} \mathrm{~S}$ and $\mathrm{C}_{3} \mathrm{~S}$ have been observed astronomically (Wootten 2002). Linear, sulfur terminated chains $\mathrm{C}_{n} \mathrm{~S}(n=1-3)$ present one of the most peculiar features in interstellar chemistry. Although these molecules are ubiquitous in cold molecular clouds OMC-1 and TMC-1 (Chernicharo et al. 1987; Petrie 1996; Yamamoto et al. 1990; Hirahara et al. 1992), in circumstellar envelopes of the protostellar object B335 (Velusamy et al. 1995), and in the outflow of the carbon star IRC+10216 (Markwick et al. 2000; Chernicharo et al. 1987; Gordon et al. 2001), their hydrogen

Send offprint requests to: Y. Osamura,

e-mail: osamura@rikkyo.ac.jp

* Present address: Department of Chemistry, University of Hawaii at Manoa, Honolulu, HI 96822, USA

e-mail: kaiser@gold.chem.hawaii.edu terminated counterparts $\mathrm{HC}_{n} \mathrm{~S}$ and $\mathrm{C}_{n} \mathrm{SH}$ have not been detected in the interstellar medium yet. However, these molecules might represent the missing source of molecular-bound sulfur in the interstellar medium. Hydrogen deficient organosulfur molecules like $\operatorname{HCS}\left(\mathrm{X}^{2} \mathrm{~A}^{\prime}\right)$ and $\mathrm{HCCS}\left(\mathrm{X}^{2} \Pi\right)$ resemble also important reaction intermediates which could lead to sulfur bearing polycyclic aromatic hydrocarbons (Kaiser et al. 1999; Kaiser et al. 2002).

Despite the importance of these sulfur carrying species in the interstellar medium, their formation mechanisms have not been well established. The very first chemical models simulating interstellar sulfur chemistry postulated the involvement of $\mathrm{S}^{+}\left({ }^{2} \mathrm{P}_{\mathrm{j}}\right)$ dominated ion-molecule reactions, for instance to synthesize $\mathrm{C}_{2} \mathrm{~S}$ via the reaction sequence (1)-(3) (Scappini \& Codella 1996) or via reactions (4) and (5) (Suzuki et al. 1992; Aschi \& Largo 2001; Markwick 2000):

$$
\begin{aligned}
& \mathrm{CCH}+\mathrm{S}^{+}\left({ }^{2} \mathrm{P}_{\mathrm{j}}\right) \rightarrow \mathrm{C}_{2} \mathrm{~S}^{+}+\mathrm{H} \\
& \mathrm{C}_{2} \mathrm{~S}^{+}+\mathrm{H}_{2} \rightarrow \mathrm{HC}_{2} \mathrm{~S}^{+}+\mathrm{H} \\
& \mathrm{HC}_{2} \mathrm{~S}^{+}+\mathrm{e}^{-} \rightarrow \mathrm{C}_{2} \mathrm{~S}+\mathrm{H} \\
& \mathrm{S}^{+}\left({ }^{2} \mathrm{P}_{\mathrm{j}}\right)+\mathrm{C}_{2} \mathrm{H}_{2} \rightarrow \mathrm{HC}_{2} \mathrm{~S}^{+}+\mathrm{H} \\
& \mathrm{HC}_{2} \mathrm{~S}^{+}+\mathrm{e}^{-} \rightarrow \mathrm{C}_{2} \mathrm{~S}+\mathrm{H}
\end{aligned}
$$

Higher sulfur terminated carbon clusters were thought to be formed via encounters of sulfur ions with astronomically observed cyclopropenylidene $\left(\mathrm{c}-\mathrm{C}_{3} \mathrm{H}_{2}\right)$ and vinylidenecarbene 
$\left(\mathrm{CCCH}_{2}\right)$ isomers (Redondo et al. 1999; Markwick et al. 2000). However, a detailed model of the circumstellar envelope surrounding IRC+10216 predicted number densities of $\mathrm{C}_{2} \mathrm{~S}$ and $\mathrm{C}_{3} \mathrm{~S}$ up to two orders of magnitude lower than actually observed (Millar \& Herbst 1990). Therefore, solely ion - molecule reactions cannot account for the abundances of astronomically observed organo sulfur molecules quantitatively. Important reaction pathways to form these species are clearly lacking.

In the following years it emerged that rapid neutral - neutral reactions can also synthesize sulfur-carrying molecules in interstellar environments (Petrie 1996). Laboratory experiments augmented by electronic structure calculations of reactions of ground state carbon atoms $\mathrm{C}\left({ }^{3} \mathrm{P}_{\mathrm{j}}\right)$ with hydrogen sulfide $\left(\mathrm{H}_{2} \mathrm{~S}\right)$ revealed explicitly the formation of the thioformyl radical $\operatorname{HCS}\left(\mathrm{X}^{2} \mathrm{~A}^{\prime}\right)$ (Kaiser et al. 1999; Ochsenfeld et al. 1999; Galland et al. 2001). Likewise, the reaction of the dicarbon molecule $\mathrm{C}_{2}\left(\mathrm{X}^{1} \Sigma_{\mathrm{g}}^{+}\right)$with hydrogen sulfide yielded the thioketenyl radical HCCS $\left(X^{2} \Pi\right)$ (Kaiser et al. 2002). The hydrogen sulfide reagent is also present in the interstellar medium and has been observed, for example, in molecular clouds TMC-1 and OMC-1, toward the star forming region SgrB2, and around the circumstellar envelope of the carbon star IRC +10216 (Thaddeus et al. 1972). Likewise, atomic carbon has been detected in OB star forming regions, in circumstellar envelopes of evolved stars IRC+10216 and $\alpha$ Orionis (van der Keen et al. 1998), in molecular clouds like Orion A and TMC-1 (Tatematsu et al. 1999), and towards the protoplanetary nebulae CRL 618 and CRL 2688 (Young 1997). The dicarbon molecule is abundant in the circumstellar shell of IRC+10216 (Tatematsu et al. 1999; Combi \& Fink 1997) and in translucent clouds (Gredel 1999; Gredel et al. 2001; van Dishoek \& Black 1989). Theory predicts further that $\mathrm{C}_{2} \mathrm{~S}$ and $\mathrm{C}_{3} \mathrm{~S}$ may be synthesized via barrier-less neutral-neutral reactions of $\mathrm{S}\left({ }^{3} \mathrm{P}_{\mathrm{j}}\right)+\mathrm{C}_{2} \mathrm{H}$ and $\mathrm{S}\left({ }^{3} \mathrm{P}_{\mathrm{j}}\right)+\mathrm{C}_{3} \mathrm{H}$ (Flores 2001a; Flores 2001b). Millar et al. (2001) extended previous reaction networks and incorporated both neutral-neutral reactions of atomic sulfur. However, although this refined model significantly increased the production of $\mathrm{C}_{2} \mathrm{~S}$ and $\mathrm{C}_{3} \mathrm{~S}$, a quantitative agreement was not reached. This suggests that key production routes to sulfur carrying molecules involving reactions of two neutral particles are still missing.

To ascertain ultimately the role of neutral-neutral reactions to form small sulfur bearing molecules in molecular clouds and to unravel the most important reactions, it is crucial to explore the underlying potential energy surfaces extensively. In this paper, we present the very first comprehensive theoretical study on the synthesis of $\mathrm{C}_{n} \mathrm{~S}$ and $\mathrm{HC}_{n} \mathrm{~S}(n=1-2)$ species in cold molecular clouds via binary reactions of two neutral species. Fifteen reactions (6)-(20) are explored in depth via electronic structure calculations:

$$
\begin{aligned}
& \mathrm{CH}\left(\mathrm{X}^{2} \Pi\right)+\mathrm{S}\left({ }^{3} \mathrm{P}\right), \\
& \mathrm{C}\left({ }^{3} \mathrm{P}\right)+\mathrm{SH}\left(\mathrm{X}^{2} \Pi\right), \\
& \mathrm{CH}\left(\mathrm{X}^{2} \Pi\right)+\mathrm{SH}\left(\mathrm{X}^{2} \Pi\right), \\
& \mathrm{S}\left({ }^{3} \mathrm{P}\right)+\mathrm{CH}_{2}\left(\mathrm{X}^{3} \mathrm{~B}_{1}\right), \\
& \mathrm{CS}\left(\mathrm{X}^{1} \Sigma^{+}\right)+\mathrm{H}_{2}\left(\mathrm{X}^{1} \Sigma_{\mathrm{g}}^{+}\right),
\end{aligned}
$$

$$
\begin{aligned}
& \mathrm{C}\left({ }^{3} \mathrm{P}\right)+\mathrm{H}_{2} \mathrm{~S}\left(\mathrm{X}^{1} \mathrm{~A}_{1}\right) \\
& \mathrm{S}\left({ }^{3} \mathrm{P}\right)+\mathrm{C}_{2} \mathrm{H}\left(\mathrm{X}^{2} \Sigma^{+}\right) \\
& \mathrm{CH}\left(\mathrm{X}^{2} \Pi\right)+\mathrm{CS}\left(\mathrm{X}^{1} \Sigma^{+}\right) \\
& \mathrm{C}_{2}\left(\mathrm{X}^{1} \Sigma_{\mathrm{g}}^{+}\right)+\mathrm{SH}\left(\mathrm{X}^{2} \Pi\right) \\
& \mathrm{C}\left({ }^{3} \mathrm{P}\right)+\mathrm{HCS}\left(\mathrm{X}^{1} \mathrm{~A}^{\prime}\right) \\
& \mathrm{C}_{2}\left(\mathrm{X}^{1} \Sigma_{\mathrm{g}}^{+}\right)+\mathrm{H}_{2} \mathrm{~S}\left(\mathrm{X}^{1} \mathrm{~A}_{1}\right) \\
& \mathrm{HCS}\left(\mathrm{X}^{2} \mathrm{~A}^{\prime}\right)+\mathrm{CH}\left(\mathrm{X}^{2} \Pi\right) \\
& \mathrm{C}_{2} \mathrm{H}\left(\mathrm{X}^{2} \Sigma^{+}\right)+\mathrm{SH}\left(\mathrm{X}^{2} \Pi\right) \\
& \left.\mathrm{C}^{3} \mathrm{P}\right)+\mathrm{H}_{2} \mathrm{CS}\left(\mathrm{X}^{1} \mathrm{~A}_{1}\right) \\
& \mathrm{CH}_{2}\left(\mathrm{X}^{3} \mathrm{~B}_{1}\right)+\mathrm{CS}\left(\mathrm{X}^{1} \Sigma^{+}\right)
\end{aligned}
$$

Due to the low number densities in molecular clouds of about $10^{4}-10^{6} \mathrm{~cm}^{-3}$, we restrict this investigation to bimolecular collisions; ternary encounters occur only once in a few $10^{9}$ years and can be neglected considering mean interstellar cloud lifetimes of $10^{6}$ years. Likewise, the translational temperature of the reactant species $(\approx 10 \mathrm{~K})$ dictates that only exoergic processes without entrance barriers are open. Finally, only reagents in their electronic and vibrational ground states are considered.

\section{Theoretical model}

The potential energy surfaces (PESs) were examined in terms of $\mathrm{ab}$ initio molecular orbital methods. We have employed the hybrid density functional B3LYP method, i.e. Becke's threeparameter non-local exchange functional (Becke 1992) with the non-local correlation functional of Lee et al. (Lee et al. 1988) and the 6-311G(d,p) basis set (Krishnan et al. 1988). The structures of the intermediates and transition states have been confirmed with the vibrational analysis; all relative energies are the corrected values of the zero-point vibrational energies with the B3LYP/6-311G(d,p) level of calculation. The coupled cluster $\operatorname{CCSD}(\mathrm{T})$ calculations with the aug-cc-pVTZ basis set (Dunning 1989) have also been performed at the optimized structures obtained with the B3LYP method in order to refine the energetics. All computations have been carried out using the GAUSSIAN 98 program package (Frisch et al. 1998). The relative energies stated in the text are the values obtained with the $\operatorname{CCSD}(\mathrm{T})$ method.

\section{Results}

\subsection{The doublet HCS potential energy surface}

Both the $\mathrm{CH}\left(\mathrm{X}^{2} \Pi\right)+\mathrm{S}\left({ }^{3} \mathrm{P}\right)$ and $\mathrm{C}\left({ }^{3} \mathrm{P}\right)+\mathrm{SH}\left(\mathrm{X}^{2} \Pi\right)$ reactions (6) and (7) present barrierless pathways to access the HCS potential energy surface (PES) (Figs. 1 and 2) yielding the thioformyl, $\operatorname{HCS}\left(\mathrm{X}^{2} \mathrm{~A}^{\prime}\right)$ (Int1), and isothioformyl, $\operatorname{HSC}\left(\mathrm{X}^{2} \mathrm{~A}^{\prime}\right)$ (Int2), radical intermediates, respectively. Both isomers are stabilized by $404 \mathrm{kJmol}^{-1}$ and $563 \mathrm{kJmol}^{-1}$ with respect to the separated $\mathrm{CH}\left(\mathrm{X}^{2} \Pi\right) / \mathrm{S}\left({ }^{3} \mathrm{P}\right)$ reactants. The energy difference of $159 \mathrm{kJmol}^{-1}$ is in excellent agreement with previous data of $161 \mathrm{kJmol}^{-1}$ (Galland et al. 2001) and $166 \mathrm{kJmol}^{-1}$ (Ochsenfeld et al. 1999) obtained at the $\operatorname{CCSD}(\mathrm{T}) / \mathrm{cc}-$ pVTZ//QCISD/cc-pVDZ and CCSD(T)/QZ3P levels of theory. 


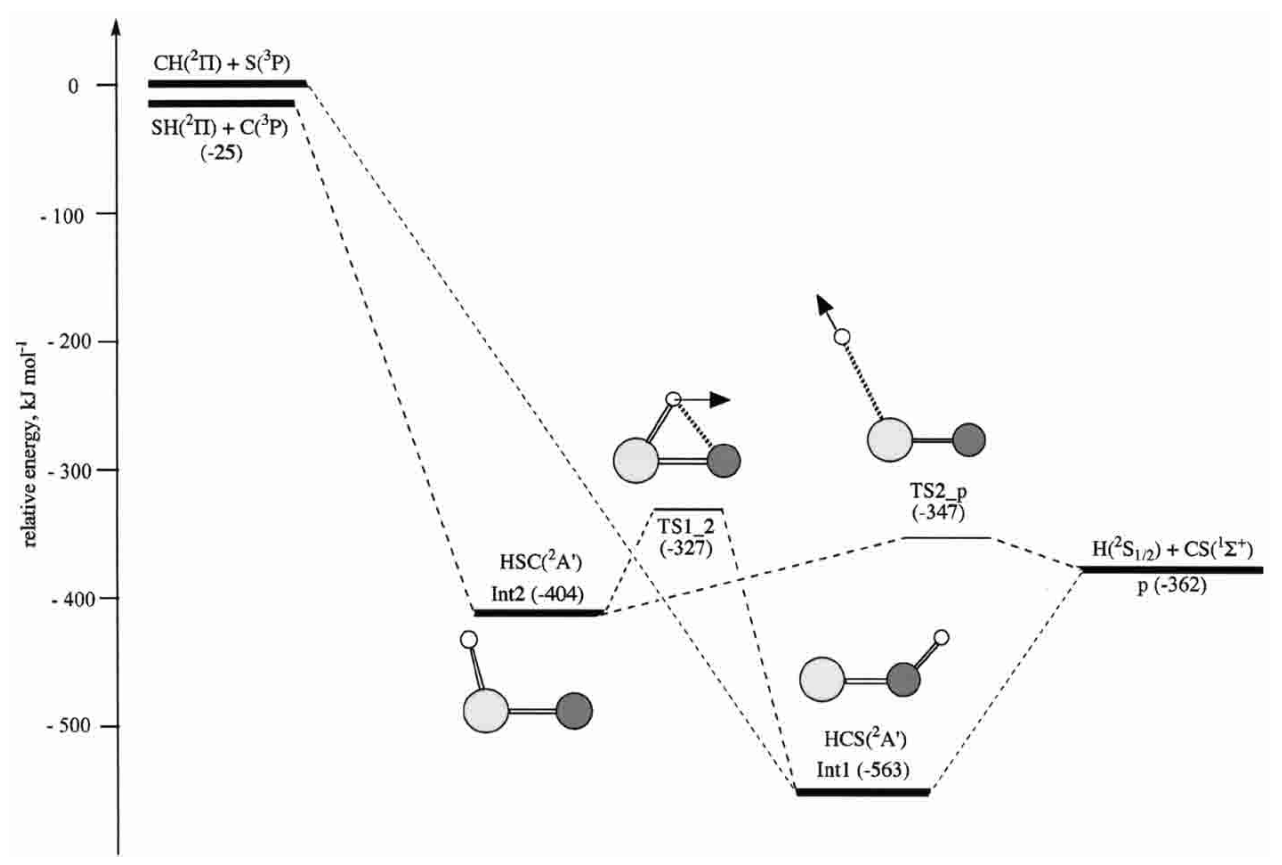

Fig. 1. Schematic representation of the doublet HCS potential energy surface. "Int" indicates an intermediate, "TS" a transition state, and "p" the products.

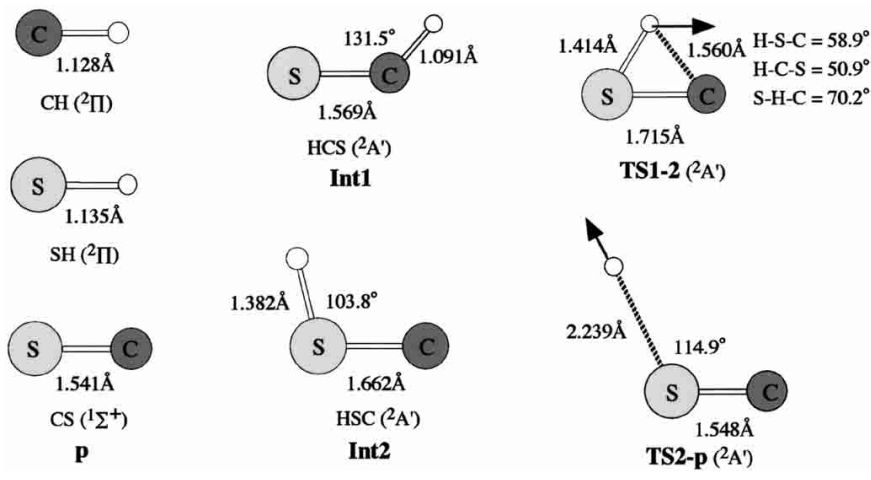

Fig. 2. Structures of reactants, intermediates, transition states, and products of the doublet HCS potential energy surface. Bond angles are given in degrees, bond distances in Angström.

$\operatorname{HCS}\left(\mathrm{X}^{2} \mathrm{~A}^{\prime}\right)$ and $\operatorname{HSC}\left(\mathrm{X}^{2} \mathrm{~A}^{\prime}\right)$ can isomerize through a barrier of $77 \mathrm{kJmol}^{-1}$ with respect to Int2 via TS1_2 and decompose via an atomic hydrogen loss to form the $\mathrm{CS}\left(\mathrm{X}^{1} \Sigma^{+}\right)+\mathrm{H}\left({ }^{2} \mathrm{~S}_{1 / 2}\right)$ products. These processes are either barrierless (from Int 1 ) or involve an exit barrier of $15 \mathrm{kJmol}^{-1}$ via TS2_p with respect to the final products. Note that an earlier study located a barrier of $5 \mathrm{kJmol}^{-1}$ for TS1_p (Galland et al. 2001). The overall reactions to form $\mathrm{CS}\left(\mathrm{X}^{1} \Sigma^{+}\right)+\mathrm{H}\left({ }^{2} \mathrm{~S}_{1 / 2}\right)$ from $\mathrm{CH}\left(\mathrm{X}^{2} \Pi\right) / \mathrm{S}\left({ }^{3} \mathrm{P}\right)$ and $\mathrm{C}\left({ }^{3} \mathrm{P}\right) / \mathrm{SH}\left(\mathrm{X}^{2} \Pi\right)$ were found to be strongly exoergic by $362 \mathrm{kJmol}^{-1}$ and $337 \mathrm{kJmol}^{-1}$, respectively.

\subsection{The $\mathrm{H}_{2} \mathrm{CS}$ potential energy surface}

\subsubsection{The singlet $\mathrm{H}_{2} \mathrm{CS}$ potential energy surface}

Both the $\mathrm{CH}\left(\mathrm{X}^{2} \Pi\right)+\mathrm{SH}\left(\mathrm{X}^{2} \Pi\right)$ and $\mathrm{S}\left({ }^{3} \mathrm{P}\right)+\mathrm{CH}_{2}\left(\mathrm{X}^{3} \mathrm{~B}_{1}\right)$ reactions (8) and (9) have no entrance barrier. The methylidene radical either adds to the terminal sulfur atom or inserts into the
$\mathrm{S}-\mathrm{H}$ bond of the $\mathrm{SH}\left(\mathrm{X}^{2} \Pi\right)$ radical to form thiohydroxycarbene (Int3, HSCH, ${ }^{1} \mathrm{~A}^{\prime}$ ) or thioformaldehyde (Int4, $\mathrm{H}_{2} \mathrm{CS}, \mathrm{X}^{1} \mathrm{~A}_{1}$ ), respectively (Figs. 3-5). The thiohydroxycarbene molecule can exist in the trans (Int3) or cis (Int $\left.3^{\prime}\right)$ form. The latter is energetically less favored by $6 \mathrm{kJmol}^{-1}$; both isomers are connected through transition states via configuration inversion of the carbon atom and rotation around the carbon-sulfur bond. The calculations show further that Int 3 and Int 4 reside in deep potential energy wells of $407 \mathrm{~kJ} \mathrm{~mol}^{-1}$ and $592 \mathrm{kJmol}^{-1}$ with respect to the separated $\mathrm{CH}\left(\mathrm{X}^{2} \Pi\right)+\mathrm{SH}\left(\mathrm{X}^{2} \Pi\right)$ reactants; the trans structure can undergo a hydrogen shift to Int4 via TS3_4 located at $132 \mathrm{kJmol}^{-1}$ above the thiohydroxy molecule. Additionally, Int3 can isomerize through hydrogen migration forming Int5 $\left(\mathrm{X}^{1} \mathrm{~A}_{1}\right)$ via TS3_5 located $89 \mathrm{kJmol}^{-1}$ above Int5. The latter is the least stable $\mathrm{H}_{2} \mathrm{CS}$ isomer on the singlet surface and only stabilized by $98 \mathrm{kJmol}^{-1}$ with respect to $\mathrm{CH}\left(\mathrm{X}^{2} \Pi\right) / \mathrm{SH}\left(\mathrm{X}^{2} \Pi\right)$. The $\mathrm{S}\left({ }^{3} \mathrm{P}\right)+\mathrm{CH}_{2}\left(\mathrm{X}^{3} \mathrm{~B}_{1}\right)$ reaction (8) proceeds via addition of atomic sulfur to the carbon atom of the methylidene radical to form Int4; no reaction pathways via an insertion of atomic sulfur into a $\mathrm{C}$-H-bond to Int3 was found. The reaction of $\mathrm{CS}\left(\mathrm{X}^{1} \Sigma^{+}\right)$with $\mathrm{H}_{2}\left(\mathrm{X}^{1} \Sigma_{\mathrm{g}}^{+}\right)(10)$ is closed in cold molecular clouds as an entrance barrier of $195 \mathrm{kJmol}^{-1}$ inhibits formation of Int4 via TS_4.

The intermediates involved can emit a hydrogen atom to form the thioformyl radical $\mathrm{HCS}\left(\mathrm{X}^{2} \mathrm{~A}^{\prime}\right)$ (from Int3, Int4) or $\mathrm{HSC}\left(\mathrm{X}^{2} \mathrm{~A}^{\prime}\right)$ (from Int3, Int5). Each atomic hydrogen elimination has no exit barrier. The pathways to form HCS and HSC from the $\mathrm{CH}\left(\mathrm{X}^{2} \Pi\right)+\mathrm{SH}\left(\mathrm{X}^{2} \Pi\right)$ reactants were found to be exoergic by $211 \mathrm{kJmol}^{-1}$ and $51 \mathrm{kJmol}^{-1}$. Therefore, the thiohydroxy isomer is expected to be the major product via an $\mathrm{H}$ atom loss. Considering the $\mathrm{S}\left({ }^{3} \mathrm{P}\right)+\mathrm{CH}_{2}\left(\mathrm{X}^{3} \mathrm{~B}_{1}\right)$ reactants, the synthesis of HSC is endoergic by $21 \mathrm{kJmol}^{-1}$ and hence not feasible in cold molecular clouds; however, the formation of 


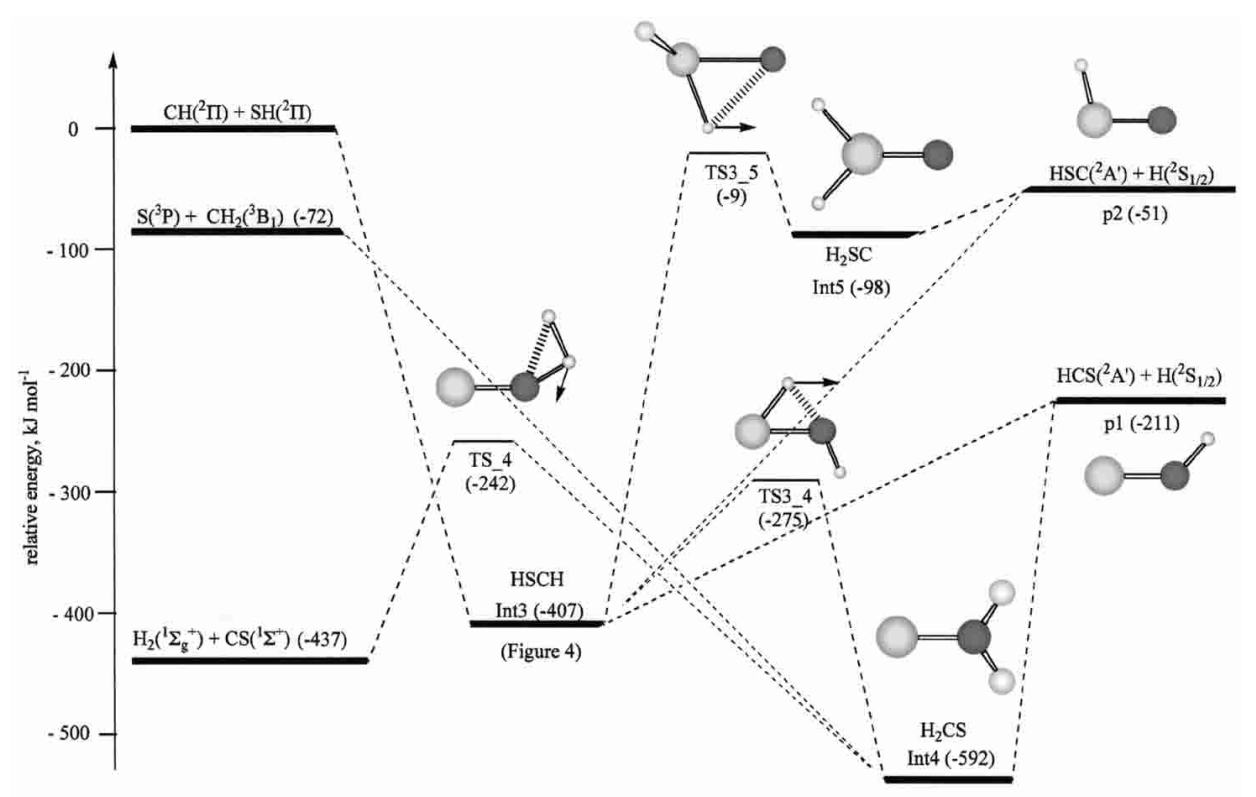

Fig. 3. Schematic representation of the singlet $\mathrm{H}_{2} \mathrm{CS}$ potential energy surface. "Int" indicates an intermediate, "TS" a transition state, and "p" the products.

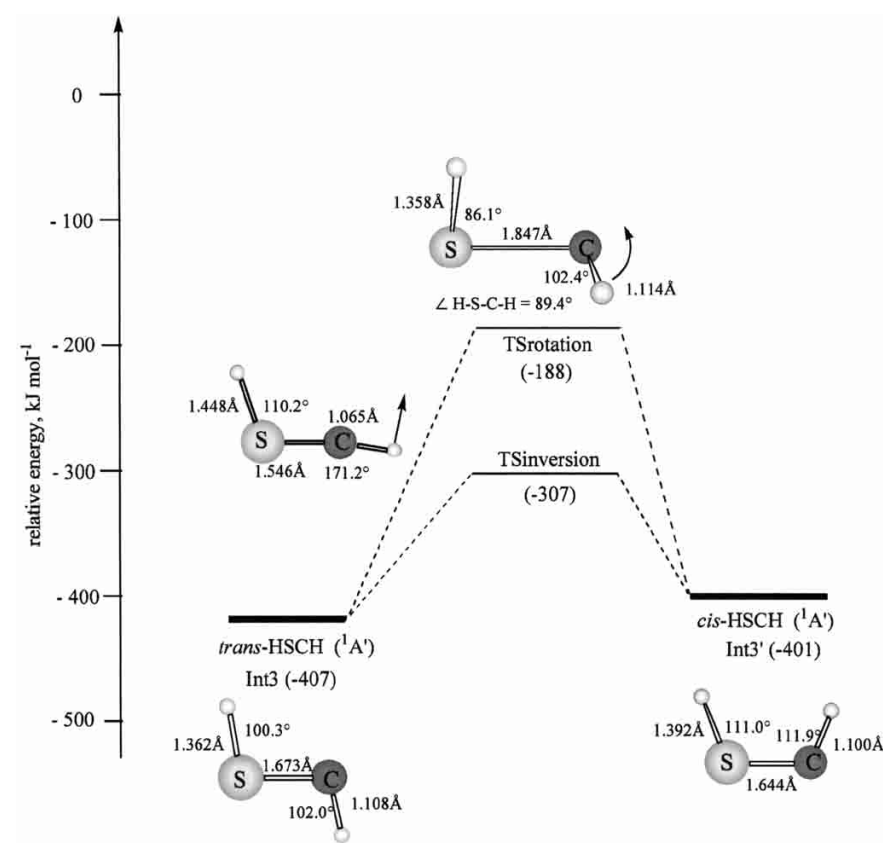

Fig. 4. Schematic representation of the isomerization of Int3. "Int" indicates an intermediate and "TS" a transition state.

the HCS isomer is open as this pathway was calculated to be exoergic by $139 \mathrm{kJmol}^{-1}$. Note, however, that Int4 can also fragment via a molecular hydrogen loss to form carbonmonosulfide $\mathrm{CS}\left(\mathrm{X}^{1} \Sigma^{+}\right)$. Here, the exit transition state is tight, and the overall reactions were found to be exoergic by $437 \mathrm{kJmol}^{-1}$ $\left(\mathrm{CH}\left(\mathrm{X}^{2} \Pi\right) / \mathrm{SH}\left(\mathrm{X}^{2} \Pi\right)\right)$ and $365 \mathrm{kJmol}^{-1}\left(\mathrm{~S}\left({ }^{3} \mathrm{P}\right) / \mathrm{CH}_{2}\left(\mathrm{X}^{3} \mathrm{~B}_{1}\right)\right)$.

\subsubsection{The triplet $\mathrm{H}_{2} \mathrm{CS}$ potential energy surface}

The reaction of $\mathrm{CH}\left(\mathrm{X}^{2} \Pi\right)$ with $\mathrm{SH}\left(\mathrm{X}^{2} \Pi\right)$ (8) presents also a barrier-less route to enter the triplet $\mathrm{H}_{2} \mathrm{CS}$ potential energy surface forming a thiohydroxycarbene intermediate (Int6, HSCH, ${ }^{3} \mathrm{~A}$ ) via a radical - radical recombination (Figs. 6 and 7). The latter is stabilized by $330 \mathrm{kJmol}^{-1}$ with respect to the separated reactants. An insertion of the methylidene reactant into the $\mathrm{S}-\mathrm{H}$ bond of $\mathrm{SH}\left(\mathrm{X}^{2} \Pi\right)$ can also form to triplet thioformaldehyde (Int7, H2CS, 3A"). This isomer resides in a potential well of $423 \mathrm{kJmol}^{-1}$ compared to the reactants and is connected to Int6 via transition state TS6_7 located $88 \mathrm{kJmol}^{-1}$ above $\mathrm{HSCH}$. The reaction of $\mathrm{C}\left({ }^{3} \mathrm{P}\right)$ with $\mathrm{H}_{2} \mathrm{~S}\left(\mathrm{X}^{1} \mathrm{~A}_{1}\right)$ leads to the triplet surface as well giving Int8 $\left(\mathrm{H}_{2} \mathrm{SC},{ }^{3} \mathrm{~A}^{\prime \prime}\right)$ without entrance barrier. This intermediate is only slightly more stable by $70 \mathrm{kJmol}^{-1}$ with respect to atomic carbon and hydrogen sulfide and can rearrange via hydrogen shift to Int6. The barrier of this process via TS6_8 was determined to be $43 \mathrm{kJmol}^{-1}$ with respect to Int8.

Similar to the singlet surface, these intermediates can fragment via various atomic hydrogen loss pathways yielding the thioformyl radical $\mathrm{HCS}\left(\mathrm{X}^{2} \mathrm{~A}^{\prime}\right.$ ) (from Int6, Int7) or $\mathrm{HSC}\left(\mathrm{X}^{2} \mathrm{~A}^{\prime}\right)$ (from Int6, Int8). The decomposition of Int8 via TS8_p2 involves a barrier of $10 \mathrm{kJmol}^{-1}$ above the final products. Previous calculations overestimated the barrier slightly by $5 \mathrm{kJmol}^{-1}$ (Galland et al. 2001). The existence of an exit barrier has important consequences: TS8_p2 is located below the energy of the separated $\mathrm{CH}\left(\mathrm{X}^{2} \Pi\right) / \mathrm{SH}\left(\mathrm{X}^{2} \Pi\right)$ reactants, but above the $\mathrm{C}\left({ }^{3} \mathrm{P}\right) / \mathrm{H}_{2} \mathrm{~S}\left(\mathrm{X}^{1} \mathrm{~A}_{1}\right)$ reagents. Therefore, HSC isomers cannot be formed via reaction (11) in cold molecular clouds. A fragmentation of Int7 to the thioformyl isomer via TS7_p1 involves an exit barrier of $5 \mathrm{kJmol}^{-1}$ with respect to the products. Since this barrier is well below the $\mathrm{CH}\left(\mathrm{X}^{2} \Pi\right) / \mathrm{SH}\left(\mathrm{X}^{2} \Pi\right)$ and $\mathrm{C}\left({ }^{3} \mathrm{P}\right) / \mathrm{H}_{2} \mathrm{~S}\left(\mathrm{X}^{1} \mathrm{~A}_{1}\right)$ reactants, the synthesis of the HCS radical is feasible even in cold molecular clouds. The $\mathrm{H}$ atom ejection from Int6 to form HSC proceeds barrier-less; the formation of HCS, however, goes via a loose transition state TS6_p1 which is situated only $2 \mathrm{kJmol}^{-1}$ above the final products. Note that an earlier study suggests that this process is barrier-less 

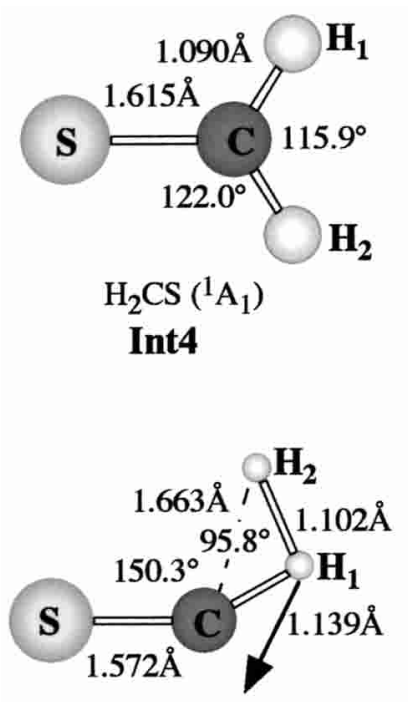

TS_4 ( $\left({ }^{1} \mathrm{~A}^{\prime}\right)$

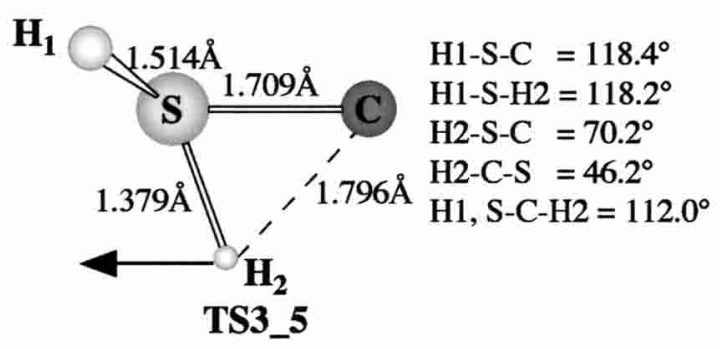

Fig. 5. Structures of intermediates and transition states of the singlet $\mathrm{H}_{2} \mathrm{CS}$ potential energy surface. Bond angles are given in degrees, bond distances in Angström. The structures of the products $\mathrm{p} 1$ and $\mathrm{p} 2$ are shown as Int1 and Int2 in Fig. 2.

(Galland et al. 2001). The overall reaction energies to form the thioformyl radical in reactions (11) and (8) is calculated to be $-169 \mathrm{kJmol}^{-1}$ and $-211 \mathrm{kJmol}^{-1}$, respectively; the formation of the HSC isomer is less exoergic by $160 \mathrm{kJmol}^{-1}$. Intrinsic reaction coordinate (IRC) calculations show that no triplet $\mathrm{H}_{2} \mathrm{CS}$ intermediate connects to molecular hydrogen and a triplet carbonmonosulfide product, $\mathrm{CS}\left(\mathrm{a}^{3} \Pi\right)$.

\subsection{The doublet $\mathrm{HC}_{2} \mathrm{~S}$ potential energy surface}

This section investigates four barrierless entrance channels to the doublet $\mathrm{HC}_{2} \mathrm{~S}$ potential energy surface via reactions (12)-(15) (Figs. 8 and 9). Binary collisions of atomic sulfur with an ethinyl radical (reaction (12)) yield the linear thioketenyl radical $\operatorname{HCCS}\left(\mathrm{X}^{2} \Pi\right)$ (Int9) which is stabilized by $458 \mathrm{kJmol}^{-1}$ compared to the separated reactant; an insertion of $\mathrm{S}\left({ }^{3} \mathrm{P}\right)$ into the acetylenic $\mathrm{C}-\mathrm{H}$-bond is not open. Reaction (13) also has no entrance barrier and proceeds via addition of $\mathrm{CH}\left(\mathrm{X}^{2} \Pi\right)$ either to the terminal carbon atom forming $\operatorname{HCCS}\left(\mathrm{X}^{2} \Pi\right)$ (Int9) or to the carbon-sulfur triple bond giving the cyclic isomer $\mathrm{c}-\mathrm{HC}_{2} \mathrm{~S}\left(\mathrm{X}^{2} \mathrm{~A}^{\prime \prime}\right)$ (Int10). The latter is less stable by $115 \mathrm{kJmol}^{-1}$ with respect to Int9. Note that an addition of $\mathrm{CH}\left(\mathrm{X}^{2} \Pi\right)$ to the sulfur atom can be excluded; the hypothetical CSCH structure presents no local minimum on the $\mathrm{HC}_{2} \mathrm{~S}$ potential energy surface. An addition of
$\mathrm{SH}\left(\mathrm{X}^{2} \Pi\right)$ to the terminal carbon atom is also important in the $\mathrm{C}_{2}\left(\mathrm{X}^{1} \Sigma_{\mathrm{g}}^{+}\right) / \mathrm{SH}\left(\mathrm{X}^{2} \Pi\right)$ system (reaction (14)); this pathway forms the bent $\mathrm{HSCC}\left(\mathrm{X}^{2} \mathrm{~A}^{\prime \prime}\right)$ isomer (Int11); compared to Int9, this structure is less stable by $193 \mathrm{kJmol}^{-1}$. The decreasing stability from Int 9 via Int 10 to Int 11 is in excellent agreement with a previous study (Flores et al. 2001) depicting relative energies of $0 \mathrm{kJmol}^{-1}$ (Int9), $117 \mathrm{kJmol}^{-1}$ (Int10), and $192 \mathrm{kJmol}^{-1}$ (Int11). Last but not least, reaction (15) leads to $\mathrm{c}-\mathrm{HC}_{2} \mathrm{~S}\left(\mathrm{X}^{2} \mathrm{~A}^{\prime \prime}\right)$ (Int10) via addition of the carbon atom to the sulfur-carbon double bond; neither an insertion into the C-H-bond nor an addition to the terminal sulfur atom of the HCS radical are viable. These intermediates can undergo various isomerization processes. Int9 shows a ring closure via TS9_10 $\left(+224 \mathrm{kJmol}^{-1}\right)$ to form Int10; the latter can ring open to the Int11 isomer via either TS10_11 or TS'10_11 (+201 or $\left.+207 \mathrm{kJmol}^{-1}\right)$. There is no pathway connecting Int9 via a single hydrogen shift to Int11. A hydrogen migration occurs only from Int9 to yield Int12 (SCHC $\left.\left(\mathrm{X}^{2} \mathrm{~A}^{\prime}\right)\right)$ via TS9_12; this intermediate Int12 is less stable by $235 \mathrm{kJmol}^{-1}$ compared to Int9.

These intermediates fragment via atomic hydrogen loss to form numerous $\mathrm{C}_{2} \mathrm{~S}$ isomers without exit barrier in strongly exoergic reactions. Our calculations suggest that the linear CCS structure $\left(\mathrm{X}^{3} \Sigma^{-}\right)(\mathrm{p} 3)$ is the most stable $\mathrm{C}_{2} \mathrm{~S}$ isomer; the $\mathrm{a}^{1} \Delta$ state is $57 \mathrm{kJmol}^{-1}$ higher in energy (p4). The investigations suggest also the existence of a cyclic $c-C_{2} S$ isomer $\left(\mathrm{X}^{1} \mathrm{~A}_{1}\right)$ (p5) ranging $80 \mathrm{kJmol}^{-1}$ above $\mathrm{p} 3$. As pointed out previously (Flores et al. 2001), the Renner-Teller effect splits the $X^{2} \Pi$ state of the HCCS radical (Int9) into a ${ }^{2} \mathrm{~A}^{\prime \prime}$ and ${ }^{2} \mathrm{~A}^{\prime}$ state; the latter correlates with the $\mathrm{C}_{2} \mathrm{~S}\left(\mathrm{X}^{3} \Sigma^{-}\right)+\mathrm{H}\left({ }^{2} \mathrm{~S}_{1 / 2}\right)$ products. The c$\mathrm{HC}_{2} \mathrm{~S}$ intermediate (Int10) decomposes without exit barrier to form $\mathrm{c}-\mathrm{C}_{2} \mathrm{~S}\left(\mathrm{X}^{1} \mathrm{~A}_{1}\right)+\mathrm{H}\left({ }^{2} \mathrm{~S}_{1 / 2}\right)$, whereas $\mathrm{HSCC}\left(\mathrm{X}^{2} \mathrm{~A}^{\prime \prime}\right)$ (Int11) fragments to the $\mathrm{C}_{2} \mathrm{~S}\left(\mathrm{X}^{3} \Sigma^{-}\right)+\mathrm{H}\left({ }^{2} \mathrm{~S}_{1 / 2}\right)$. Finally, $\mathrm{SCHC}\left(\mathrm{X}^{2} \mathrm{~A}^{\prime}\right)$ (Int12) can lose a hydrogen atom forming $\mathrm{C}_{2} \mathrm{~S}\left(a^{1} \Delta\right)$. Note, however, that a non-planar geometry of Int12 correlates with the $\mathrm{C}_{2} \mathrm{~S}\left(\mathrm{X}^{3} \Sigma^{-}\right)+\mathrm{H}\left({ }^{2} \mathrm{~S}_{1 / 2}\right)$ products.

The reaction exoergicity to form the $\mathrm{C}_{2} \mathrm{~S}\left(\mathrm{X}^{3} \Sigma^{-}\right)+\mathrm{H}\left({ }^{2} \mathrm{~S}_{1 / 2}\right)$ via reaction (12) was calculated to be $-31 \mathrm{kJmol}^{-1}$. Therefore, only $\mathrm{C}_{2} \mathrm{~S}\left(\mathrm{X}^{3} \Sigma^{-}\right)$can be formed in cold molecular clouds, whereas the formation of $c-C_{2} S\left(X^{1} A_{1}\right)$ and $C_{2} S\left(a^{1} \Delta\right)$ is closed. However, since the enthalpies of formations of the reagents (reactions (13)-(15)) are larger by $28 \mathrm{kJmol}^{-1}, 119 \mathrm{kJmol}^{-1}$, and $154 \mathrm{kJmol}^{-1}$ with respect to the $\mathrm{S}\left({ }^{3} \mathrm{P}\right) / \mathrm{C}_{2} \mathrm{H}\left(\mathrm{X}^{2} \Sigma^{+}\right)$system, $\mathrm{C}_{2} \mathrm{~S}\left(\mathrm{X}^{3} \Sigma^{-}\right), \mathrm{C}_{2} \mathrm{~S}\left(a^{1} \Delta\right)$, and $\mathrm{c}-\mathrm{C}_{2} \mathrm{~S}\left(\mathrm{X}^{1} \mathrm{~A}_{1}\right)$ might be formed in these systems via exoergic pathways. The calculations of the branching ratios is currently under investigation; but based on the energetics, we expect $\mathrm{C}_{2} \mathrm{~S}\left(\mathrm{X}^{3} \Sigma^{-}\right)$to be the dominant product, whereas the cyclic structure should be less prominent. Once $c-\mathrm{C}_{2} \mathrm{~S}\left(\mathrm{X}^{1} \mathrm{~A}_{1}\right)$ is formed, this structure is stable in cold molecular clouds towards ring opening; we determined the inherent barrier to the $\mathrm{C}_{2} \mathrm{~S}\left(a^{1} \Delta\right)$ isomer to be $81 \mathrm{kJmol}^{-1}$ - well above the averaged translational temperature in these environments (Fig. 10).

\subsection{The $\mathrm{H}_{2} \mathrm{C}_{2} \mathrm{~S}$ potential energy surface}

\subsubsection{The singlet $\mathrm{H}_{2} \mathrm{C}_{2} \mathrm{~S}$ potential energy surface}

The singlet $\mathrm{H}_{2} \mathrm{C}_{2} \mathrm{~S}$ potential energy surface is shown in Fig. 11. All reactions (16)-(18) present barrier-less pathways to form 


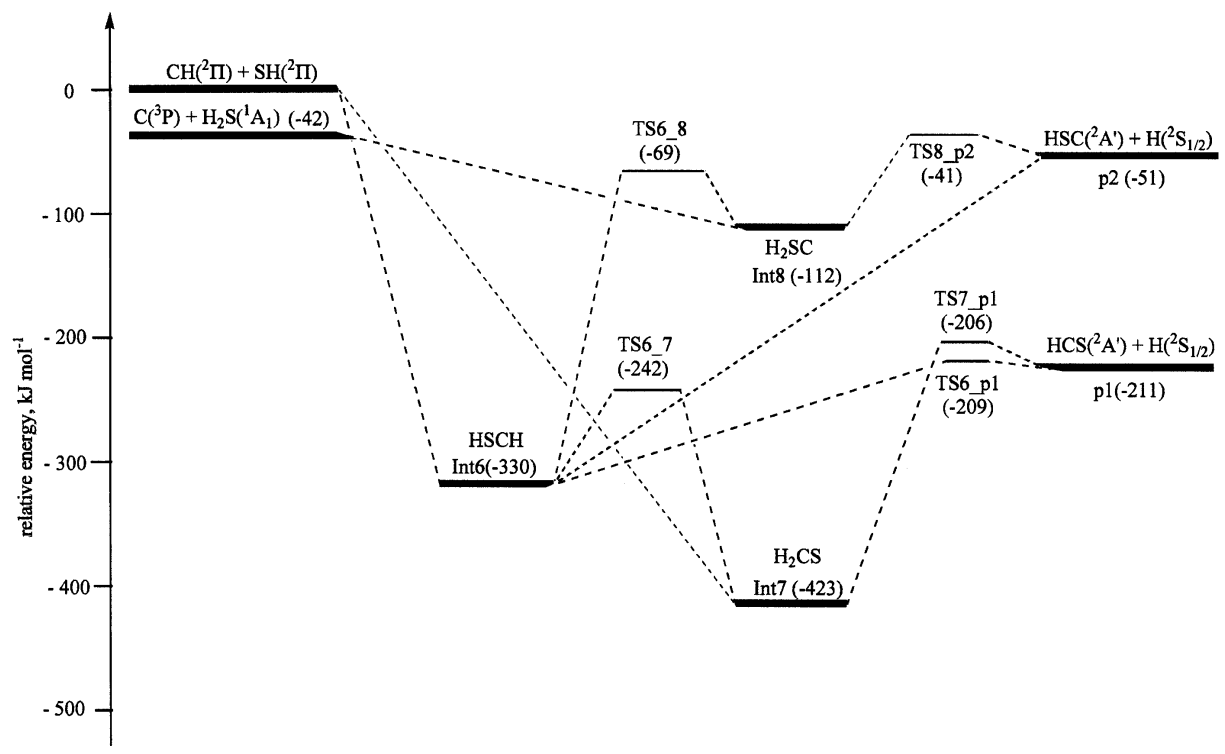

Fig. 6. Schematic representation of the triplet $\mathrm{H}_{2} \mathrm{CS}$ potential energy surface. "Int" indicates an intermediate, "TS" a transition state, and "p" the products.
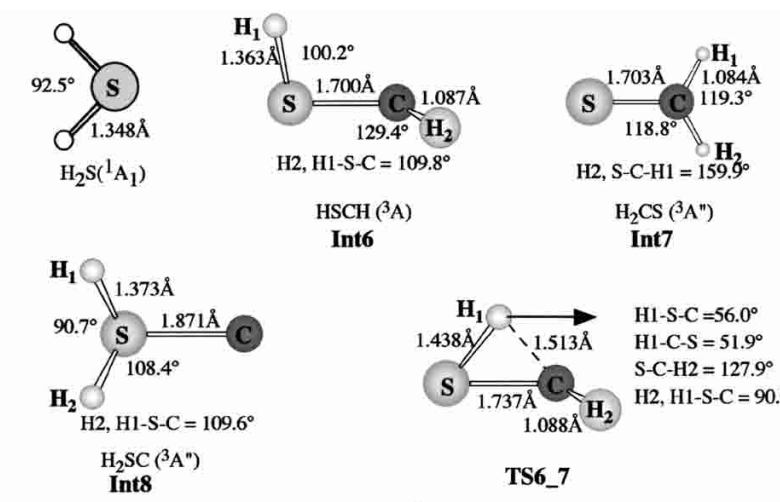

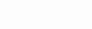
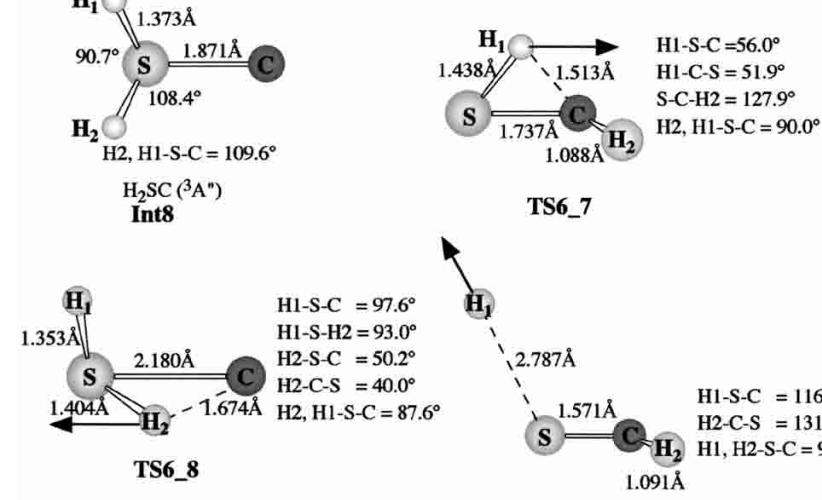

TS6_7
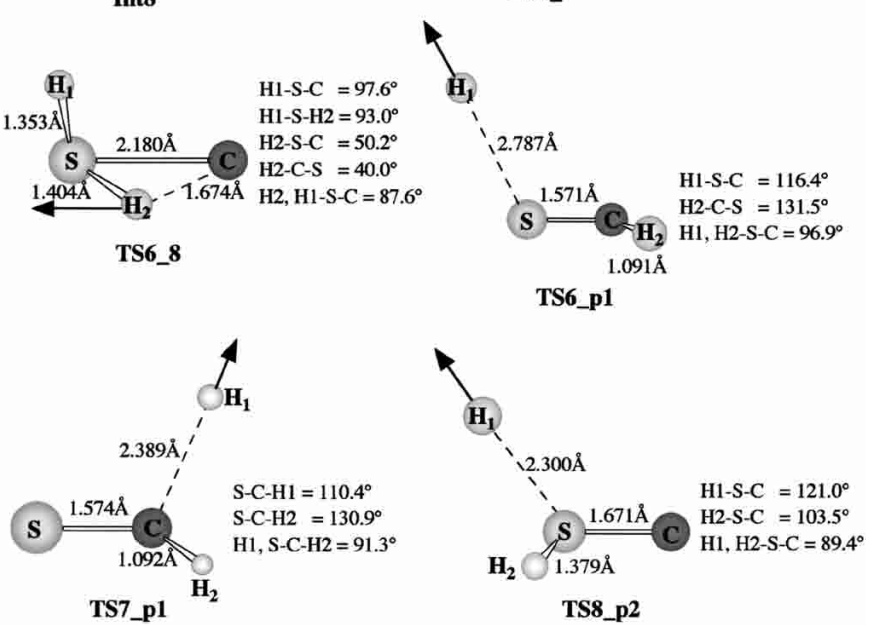

Fig. 7. Structures of reactants, intermediates, and transition states of the triplet $\mathrm{H}_{2} \mathrm{CS}$ potential energy surface. Bond angles are given in degrees, bond distances in Angström. The structures of the products p1 and p2 are shown as Int1 and Int 2 in Fig. 2.

strongly bound $\mathrm{H}_{2} \mathrm{C}_{2} \mathrm{~S}$ intermediates. The dicarbon molecule reacts with hydrogen sulfide via addition to the sulfur atom of $\mathrm{H}_{2} \mathrm{~S}\left(\mathrm{X}^{1} \mathrm{~A}_{1}\right)$ giving $\mathrm{H}_{2} \mathrm{SCC}\left(\mathrm{X}^{1} \mathrm{~A}^{\prime}\right)$ (Int13) which is stabilized by $194 \mathrm{kJmol}^{-1}$ with respect to the separated reactants
(Fig. 12). The radical-radical recombination of $\mathrm{C}_{2} \mathrm{H}\left(\mathrm{X}^{2} \Sigma^{+}\right)$ and $\mathrm{SH}\left(\mathrm{X}^{2} \Pi\right)$ leads to thiohydroxyacetylene $\mathrm{HSCCH}\left(\mathrm{X}^{1} \mathrm{~A}^{\prime}\right)$ (Int14); this isomer is more stable by $330 \mathrm{kJmol}^{-1}$ compared to Int13. Finally, the reaction of $\mathrm{HCS}\left(\mathrm{X}^{2} \mathrm{~A}^{\prime}\right)$ with $\mathrm{CH}\left(\mathrm{X}^{2} \Pi\right)$ can follow an insertion and addition pathway to thioketene $\mathrm{H}_{2} \mathrm{CCS}\left(\mathrm{X}^{1} \mathrm{~A}_{1}\right)$ (Int15) and cyclothiopropene $\mathrm{c}-\mathrm{C}_{2} \mathrm{H}_{2} \mathrm{~S}\left(\mathrm{X}^{1} \mathrm{~A}_{1}\right)$ (Int16), respectively. Thioketene represents the global minimum of the singlet $\mathrm{H}_{2} \mathrm{C}_{2} \mathrm{~S}$ surface and resides in a deep potential energy well of $585 \mathrm{kJmol}^{-1}$ with respect to $\mathrm{C}_{2}\left(\mathrm{X}^{1} \Sigma_{\mathrm{g}}^{+}\right)$ plus $\mathrm{H}_{2} \mathrm{~S}\left(\mathrm{X}^{1} \mathrm{~A}_{1}\right)$; compared to this isomer, the cyclic structure Int16 is less stable by $136 \mathrm{kJmol}^{-1}$ and can isomerize via hydrogen shift through TS16_17 to $\mathrm{c}-\mathrm{H}_{2} \mathrm{CCS}\left(\mathrm{X}^{1} \mathrm{~A}^{\prime}\right)$ (Int17). Note that Int 17 can be formally synthesized, for instance in cometary comae, via an addition of electronically excited carbon atoms $\left(\mathrm{C}\left({ }^{1} \mathrm{D}\right)\right)$ to thioformaldehyde $\left(\mathrm{H}_{2} \mathrm{CS}\right)$. $\mathrm{HSCHC}\left(\mathrm{X}^{1} \mathrm{~A}\right)$ (Int18) presents also a stable minimum and is energetically favorable by $173 \mathrm{kJmol}^{-1}$ compared to Int13; Int18 connects Int13 and Int14 via TS13_18 and TS14_18 via two hydrogen shifts. All intermediates involved can isomerize through various transition states via hydrogen migration (TS14_15) and ring openings/closures (TS16_18, TS15_16, TS15_17).

The singlet $\mathrm{H}_{2} \mathrm{C}_{2} \mathrm{~S}$ intermediates can fragment via atomic hydrogen loss to form various $\mathrm{HC}_{2} \mathrm{~S}$ isomers. These are $\operatorname{HCCS}\left(\mathrm{X}^{2} \Pi\right)$ (from Int14 and Int15), $\mathrm{c}-\mathrm{C}_{2} \mathrm{~S}\left(\mathrm{X}^{1} \mathrm{~A}_{1}\right)$ (from Int16, Int17 and Int18), $\operatorname{HSCC}\left(\mathrm{X}^{2} \mathrm{~A}^{\prime \prime}\right)$ (from Int13 and Int14), and $\mathrm{SCHC}\left(\mathrm{X}^{2} \mathrm{~A}^{\prime}\right)$ (from Int17). The energetics depend strongly on the nature of the reagent molecules (reactions (16)-(18)); considering the $\mathrm{C}_{2}\left(\mathrm{X}^{1} \Sigma_{\mathrm{g}}^{+}\right) / \mathrm{H}_{2} \mathrm{~S}\left(\mathrm{X}^{1} \mathrm{~A}_{1}\right)$ system, the formation of $\mathrm{HCCS}\left(\mathrm{X}^{2} \Pi\right)+\mathrm{H}\left({ }^{2} \mathrm{~S}_{1 / 2}\right)$ is exoergic by $208 \mathrm{kJmol}^{-1}$, of c- $\mathrm{C}_{2} \mathrm{~S}\left(\mathrm{X}^{1} \mathrm{~A}_{1}\right)$ by $93 \mathrm{kJmol}^{-1}$, and of $\mathrm{HSCC}\left(\mathrm{X}^{2} \mathrm{~A}^{\prime \prime}\right)$ by only $15 \mathrm{kJmol}^{-1}$. Reaction (16) cannot synthesize $\mathrm{SCHC}\left(\mathrm{X}^{2} \mathrm{~A}^{\prime}\right)$ in molecular clouds as this pathway is endoergic by $27 \mathrm{kJmol}^{-1}$. However, due to the larger enthalpies of formation of the reactants in (17) $\left(+77 \mathrm{kJmol}^{-1}\right)$, even the synthesis of $\mathrm{SCHC}\left(\mathrm{X}^{2} \mathrm{~A}^{\prime}\right)$ is energetically feasible in this system. In strong contrast, the energy of the $\mathrm{C}_{2} \mathrm{H}\left(\mathrm{X}^{2} \Sigma^{+}\right) / \mathrm{SH}\left(\mathrm{X}^{2} \Pi\right)$ reactants is much lower 


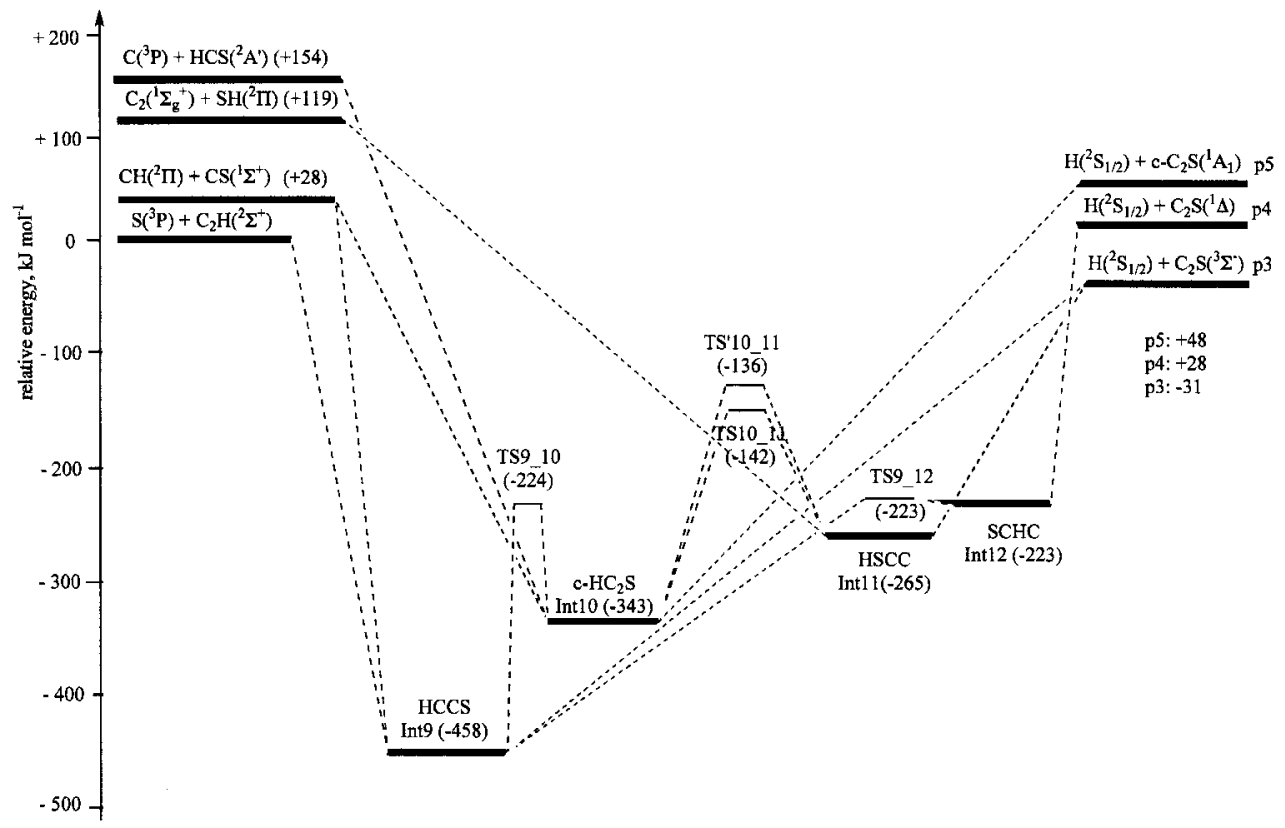

Fig. 8. Schematic representation of the doublet $\mathrm{HC}_{2} \mathrm{~S}$ potential energy surface. "Int" indicates an intermediate, "TS" a transition state, and "p" the products.
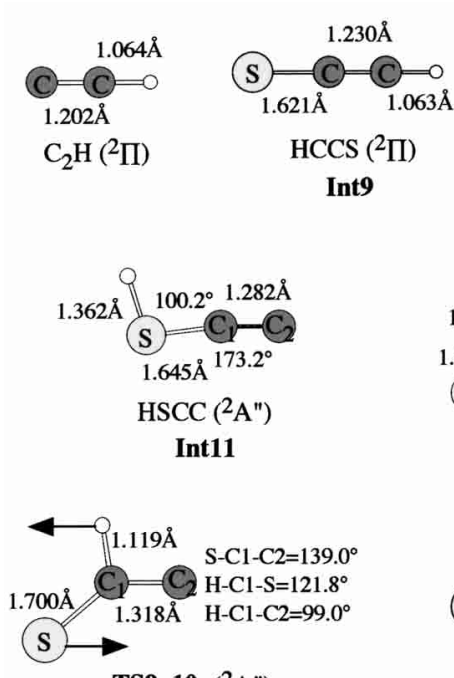

TS9_10 ( ${ }^{2}$ A")

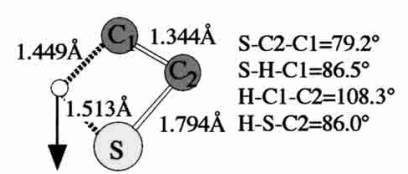

TS10_11 (2A")
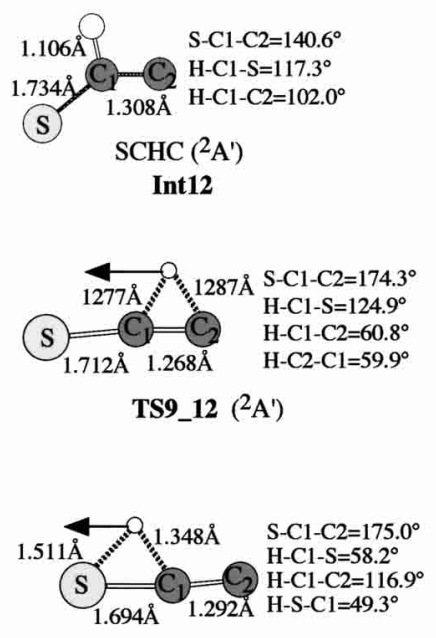

TS'10_11 ( $\left.{ }^{2} \mathrm{~A} "\right)$

Fig. 9. Structures of reactants, intermediates, and transition states of the doublet $\mathrm{HC}_{2} \mathrm{~S}$ potential energy surface. Bond angles are given in degrees, bond distances in Angström. The structures of the products p3, p4, and p5 are shown in Fig. 10.

(by $88 \mathrm{kJmol}^{-1}$ ) compared to the $\mathrm{C}_{2}\left(\mathrm{X}^{1} \Sigma_{\mathrm{g}}^{+}\right) / \mathrm{H}_{2} \mathrm{~S}\left(\mathrm{X}^{1} \mathrm{~A}_{1}\right)$ system. Note that in all systems studied, the reversed reactions of the $\mathrm{HC}_{2} \mathrm{~S}$ isomers with the hydrogen atom were found to have no entrance barriers. Our studies located also three transition states of a molecular hydrogen loss (Fig. 13). All

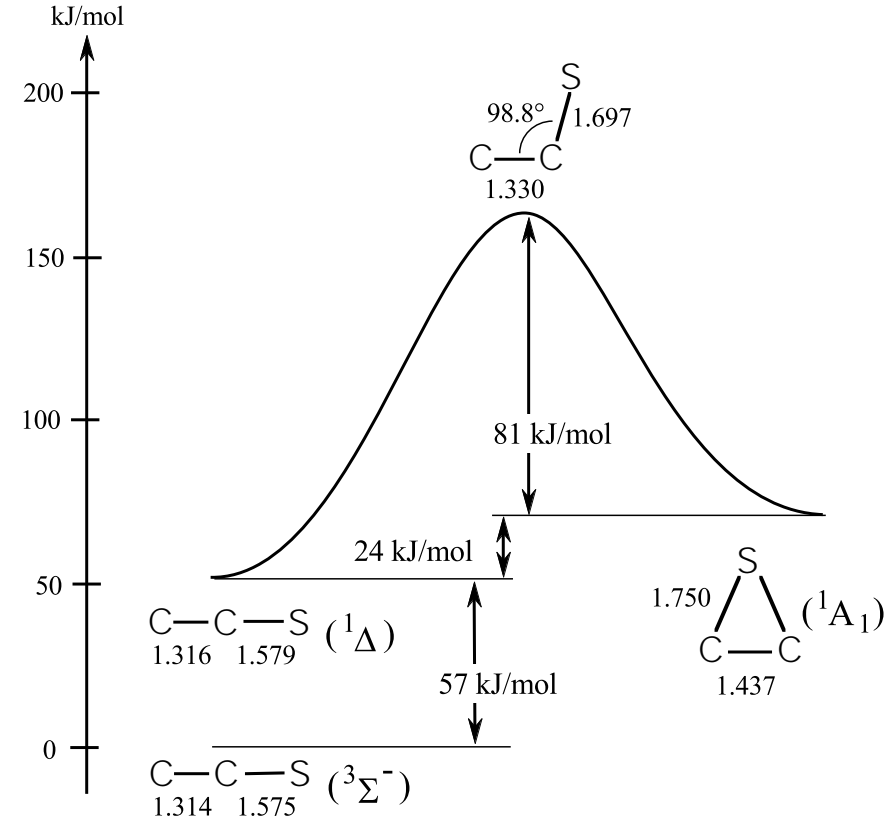

Fig. 10. Schematic representation of the isomerization of singlet $\mathrm{C}_{2} \mathrm{~S}$ isomers. Bond angles are given in degrees, bond distances in Angström.

transition states involved are well-below the energies of the separated $\mathrm{C}_{2}\left(\mathrm{X}^{1} \Sigma_{\mathrm{g}}^{+}\right)+\mathrm{H}_{2} \mathrm{~S}\left(\mathrm{X}^{1} \mathrm{~A}_{1}\right)$ reactants and hence open. However, the $\mathrm{H}_{2}$ loss channels are closed in reaction (18) as they are endoergic. Therefore, only reactions (16) and (17) can form interstellar $\mathrm{C}_{2} \mathrm{~S}$ isomers in cold molecular clouds. 


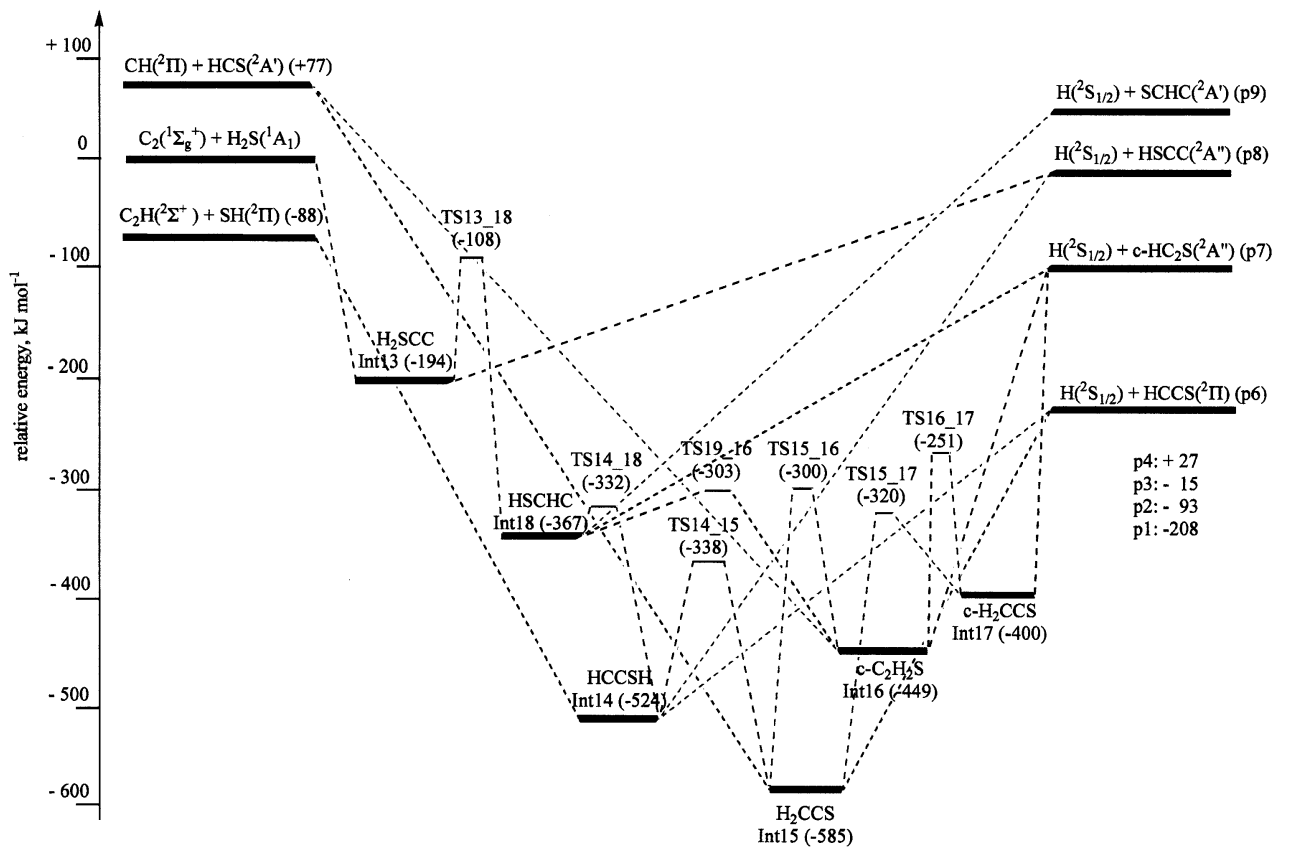

Fig. 11. Schematic representation of the singlet $\mathrm{H}_{2} \mathrm{C}_{2} \mathrm{~S}$ potential energy surface. "Int" indicates an intermediate, "TS" a transition state, and "p" the products.

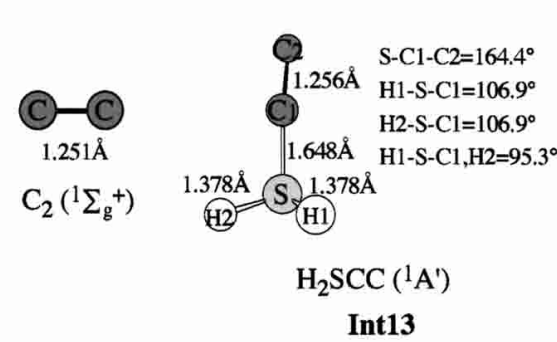

Int13

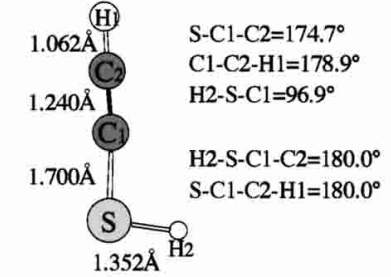

$\operatorname{HSCCH}\left({ }^{1} \mathrm{~A}^{\prime}\right)$

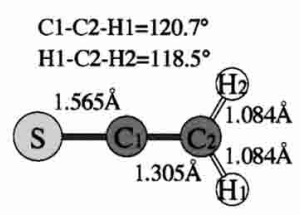

$\mathrm{H}_{2} \operatorname{CCS}\left({ }^{1} \mathrm{~A}_{1}\right)$

Int15

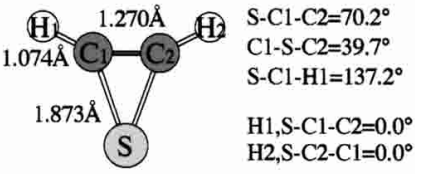

cyclic- $\mathrm{C}_{2} \mathrm{H}_{2} \mathrm{~S}\left({ }^{1} \mathrm{~A}_{1}\right)$

Int16

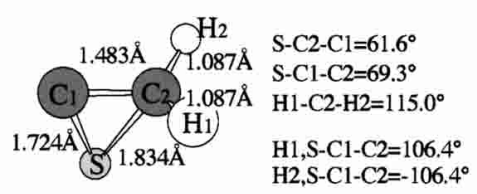

cyclic- $\mathrm{H}_{2} \mathrm{CCS}\left({ }^{1} \mathrm{~A}^{\prime}\right)$

Int17

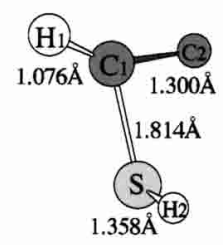

$\operatorname{HSCHC}\left({ }^{1} \mathrm{~A}\right)$

Int18

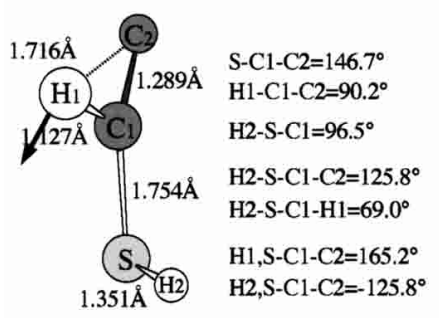

TS14_18

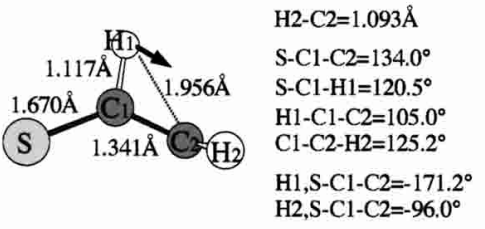

TS15_16

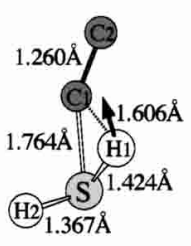

TS13_18

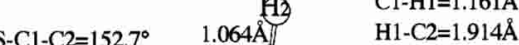
$\mathrm{H} 1 \mathrm{~S}-\mathrm{Cl}=59.4^{\circ} \quad \mathrm{C} 2 \mathrm{~S}-\mathrm{Cl}-\mathrm{H} 1=78.2^{\circ}$ $\left.\mathrm{H} 2-\mathrm{S}-\mathrm{Cl}=102.0^{\circ} \quad 1.242 \AA\right] \mathrm{H} 1-\mathrm{Cl}-\mathrm{C} 2=105.6^{\circ}$ $\mathrm{H} 1-\mathrm{S}-\mathrm{H} 2=95.3^{\circ}$ Ch $\mathrm{S}-\mathrm{Cl}-\mathrm{C} 2=176.3^{\circ}$ $1.703 \AA \quad \mathrm{C} 1-\mathrm{C} 2-\mathrm{H} 2=171.6^{\circ}$ (S) $\begin{aligned} \mathrm{H} 1, \mathrm{~S}-\mathrm{C} 1-\mathrm{C} 2=179.4^{\circ} \\ \mathrm{H} 2, \mathrm{~S}-\mathrm{Cl} 1-\mathrm{C} 2=180.0^{\circ}\end{aligned}$ TS14_15

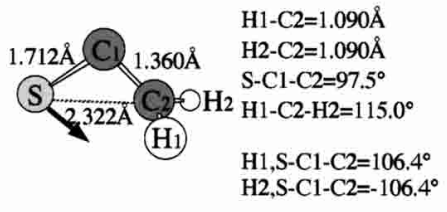

TS15_17

$\mathrm{H} 1-\mathrm{C} 1=1.321 \AA$

$\mathrm{H} 1-\mathrm{C} 2=1.321 \AA$

$\mathrm{S}-\mathrm{C} 2-\mathrm{C} 1=81.7^{\circ}$ $\mathrm{S}-\mathrm{C} 2-\mathrm{H} 2=135.8^{\circ}$ $\mathrm{C} 1-\mathrm{H} 1-\mathrm{C} 2=61.6^{\circ}$

$\mathrm{H} 1, \mathrm{~S}-\mathrm{C} 1-\mathrm{C} 2=111.3^{\circ}$ $\mathrm{H} 2, \mathrm{~S}-\mathrm{Cl}-\mathrm{C} 2=-165.6^{\circ}$

TS16_17

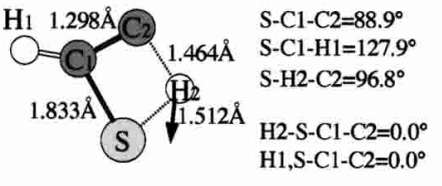

TS16_18

Fig. 12. Structures of reactants, intermediates, and transition states of the singlet $\mathrm{H}_{2} \mathrm{C}_{2} \mathrm{~S}$ potential energy surface. Bond angles are given in degrees, bond distances in Angström. The structures of the products p6-p9 are shown as Int9-Int12 in Fig. 9. 


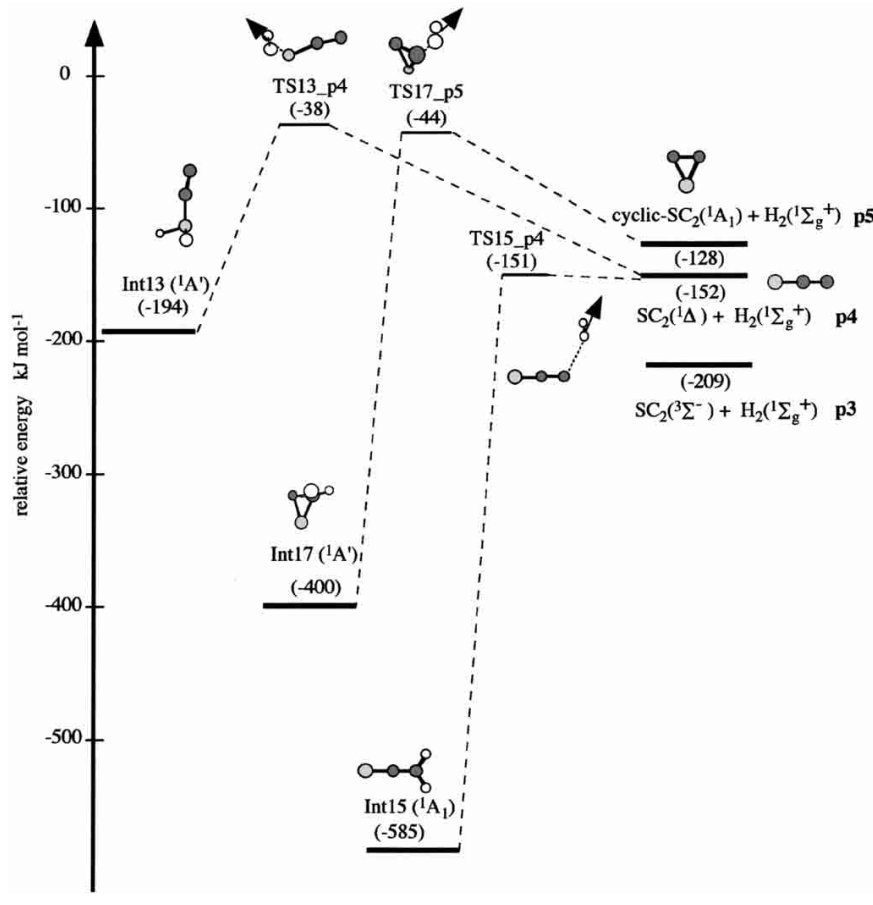

Fig. 13. Schematic representation of the molecular hydrogen elimination to form singlet $\mathrm{C}_{2} \mathrm{~S}$ isomers on the singlet $\mathrm{H}_{2} \mathrm{C}_{2} \mathrm{~S}$ potential energy surface.

\subsubsection{The triplet $\mathrm{H}_{2} \mathrm{C}_{2} \mathrm{~S}$ potential energy surface}

Figures 14-16 depict the simplified triplet $\mathrm{H}_{2} \mathrm{C}_{2} \mathrm{~S}$ potential energy surface together with the structures of transition states, intermediates, and products involved. All reactions (17)-(20) were found to have no entrance barrier and form deeply bound triplet $\mathrm{H}_{2} \mathrm{C}_{2} \mathrm{~S}$ intermediates. The recombination of the $\mathrm{C}_{2} \mathrm{H}\left(\mathrm{X}^{2} \Sigma^{+}\right)$and $\mathrm{SH}\left(\mathrm{X}^{2} \Pi\right)$ radicals (reaction (18)) yields triplet thiohydroxyacetylene structures HCCSH (Int19). It is important to note that this isomer exists in a cis (Int19; $\left.{ }^{3} \mathrm{~A}\right)$, transcis (Int19'; $\left.{ }^{3} \mathrm{~A}^{\prime \prime}\right)$, and trans-trans forms (Int19"; ${ }^{3} \mathrm{~A}^{\prime \prime}$ ) which are stabilized by $181 \mathrm{kJmol}^{-1}, 170 \mathrm{kJmol}^{-1}$, and $171 \mathrm{kJmol}^{-1}$ with respect to the separated reactants. The isomerization involves barriers of $107 \mathrm{kJmol}^{-1}$ (TS19_19') and $89 \mathrm{kJmol}^{-1}$ (TS19'_TS19"), respectively. Reaction (17) of $\operatorname{HCS}\left(\mathrm{X}^{2} \mathrm{~A}^{\prime}\right)$ with $\mathrm{CH}\left(\mathrm{X}^{2} \Pi\right)$ can proceed via insertion and an addition forming thioketene $\mathrm{H}_{2} \mathrm{CCS}\left(\mathrm{a}^{3} \mathrm{~A}^{\prime \prime}\right.$ ) (Int20) or cyclothiopropene (Int21). The two hydrogen atoms of this cyclic isomer are either located trans $\left({ }^{3} \mathrm{~B}\right.$; Int21) or cis $\left({ }^{3} \mathrm{~A}^{\prime \prime} ;\right.$ Int $\left.21^{\prime}\right)$ with respect to the ring. These structures are more stable by $182 \mathrm{kJmol}^{-1}$ (Int20) and $79 \mathrm{kJmol}^{-1}$ (Int21; Int21') compared to Int19. Binary collisions of carbon atoms $\left(\mathrm{C}\left({ }^{3} \mathrm{P}\right)\right)$ with thioformaldehyde $\mathrm{H}_{2} \mathrm{CS}\left(\mathrm{X}^{1} \mathrm{~A}_{1}\right)$ give another cyclic isomer c-CSCH $2\left({ }^{3} \mathrm{~A}^{\prime \prime} ; \mathrm{Int} 22\right)$ which resides in a potential energy well of $210 \mathrm{kJmol}^{-1}$ with respect to $\mathrm{C}_{2} \mathrm{H}\left(\mathrm{X}^{2} \Sigma^{+}\right)$plus $\mathrm{SH}\left(\mathrm{X}^{2} \Pi\right)$. Triplet thioketene (Int20) can be also accessed via reaction (20) of $\operatorname{CS}\left(\mathrm{X}^{1} \Sigma^{+}\right)$with $\mathrm{CH}_{2}\left(\mathrm{X}^{3} \mathrm{~B}_{1}\right)$. The remaining $\mathrm{H}_{2} \mathrm{C}_{2} \mathrm{~S}$ structures HSCHC (Int23) and $\mathrm{SCHCH}$ (Int24) cannot be formed instantly from the reactants via reactions (17)-(20). Both isomers exist in a trans $\left({ }^{3} \mathrm{~A}^{\prime \prime}\right.$, Int $23 ;{ }^{3} \mathrm{~A}^{\prime \prime}$, Int 24$)$ or cis $\left({ }^{3} \mathrm{~A}^{\prime \prime}\right.$, Int $23^{\prime} ;{ }^{3} \mathrm{~A}^{\prime \prime}$, Int $\left.24^{\prime}\right)$ form and are stabilized by $145 \mathrm{kJmol}^{-1}, 137 \mathrm{kJmol}^{-1}, 318 \mathrm{kJmol}^{-1}$, and $308 \mathrm{kJmol}^{-1}$ compared to the $\mathrm{C}_{2} \mathrm{H}\left(\mathrm{X}^{2} \Sigma^{+}\right)$and $\mathrm{SH}\left(\mathrm{X}^{2} \Pi\right)$ reactants. Note that the trans and cis forms are connected via transition states TS23_23' and TS24_24' located $125 \mathrm{kJmol}^{-1}$ and $93 \mathrm{kJmol}^{-1}$ above the trans structure; the trans structures can also isomerize through TS23_24. Int19-Int24 were found to rearrange via various transition state structures of hydrogen shifts and ring opening/closures. Note that the reaction of atomic sulfur with acetylene can also lead to triplet $\mathrm{H}_{2} \mathrm{C}_{2} \mathrm{~S}$ intermediates. However, this reaction has an entrance barrier between $8-15 \mathrm{kJmol}^{-1}$. Our calculations show further that the reaction of $\mathrm{H}_{2}\left(\mathrm{X}^{1} \Sigma_{\mathrm{g}}^{+}\right)$with $\mathrm{C}_{2} \mathrm{~S}\left(\mathrm{X}^{3} \Sigma^{-}\right)$to form $\operatorname{HCCS}\left(\mathrm{X}^{2} \Pi\right)$ and atomic hydrogen has also an entrance barrier $\left(+67 \mathrm{kJmol}^{-1}\right)$. Therefore, these pathways are closed in cold molecular clouds. It is important to stress that the reaction of electronically excited dicarbon, $\mathrm{C}_{2}\left(\mathrm{a}^{3} \Pi_{\mathrm{u}}\right)$, which is present in cometary comae, does not form any triplet $\mathrm{H}_{2} \mathrm{C}_{2} \mathrm{~S}$ intermediates. Instead, both reactants yield a cyclic van-der-Waals complex followed by an hydrogen abstraction to yield $\mathrm{C}_{2} \mathrm{H}\left(\mathrm{X}^{2} \Sigma^{+}\right)$and $\mathrm{SH}\left(\mathrm{X}^{2} \Pi\right)$ (Fig. 17).

The triplet intermediates decompose via atomic hydrogen loss. With respect to the separated $\mathrm{C}_{2} \mathrm{H}\left(\mathrm{X}^{2} \Sigma^{+}\right)$and $\mathrm{SH}\left(\mathrm{X}^{2} \Pi\right)$ reactants, the formation of $\operatorname{HCCS}\left(\mathrm{X}^{2} \Pi\right)$ p6 is exoergic by $170 \mathrm{kJmol}^{-1}$. The pathway to form p8-p9 are endoergic and hence closed in molecular clouds. Note that the enthalpies of formation of the reagents in reaction (17) are larger by $115 \mathrm{kJmol}^{-1}$ compared to (18), and p7-p9 can be also formed. Considering reaction (19), the enhanced reagents enthalpies of formation of $+62 \mathrm{kJmol}^{-1}$ suggests that the synthesis of p6-p8 is feasible. Finally, our calculations show that $\mathrm{CS}\left(\mathrm{X}^{1} \Sigma^{+}\right) / \mathrm{CH}_{2}\left(\mathrm{X}^{3} \mathrm{~B}_{1}\right)$ range $89 \mathrm{kJmol}^{-1}$ below the $\mathrm{C}_{2} \mathrm{H}\left(\mathrm{X}^{2} \Sigma^{+}\right) / \mathrm{SH}\left(\mathrm{X}^{2} \Pi\right)$ system. Therefore, no $\mathrm{HC}_{2} \mathrm{~S}$ isomer can be formed via reaction (20). Intrinsic reaction coordinate calculations depict that a molecular hydrogen elimination to form $\mathrm{C}_{2} \mathrm{~S}$ isomers does not take place on the triplet surface.

\section{Astrophysical implications}

The electronic structure calculations revealed distinct pathways to form various $\mathrm{C}_{n} \mathrm{~S}$ and $\mathrm{HC}_{n} \mathrm{~S}$ isomers $(n=1-2)$ in cold molecular clouds via bimolecular reactions between two neutral particles. This comprehensive study suggests that thirteen reactions investigated have no entrance barrier and proceed via indirect reaction dynamics through the formation of polyatomic intermediates. These structures were found to decompose predominantly via atomic hydrogen loss to form HCS and HCCS isomers; singlet intermediates can lose also molecular hydrogen giving the sulfur bearing carbon molecules CS and $\mathrm{C}_{2} \mathrm{~S}$, respectively (Fig. 18). On the HCS potential energy surface, $\mathrm{CS}\left(\mathrm{X}^{1} \Sigma^{+}\right)$was found to be the sole reaction products. Incorporating a second hydrogen atom leads to the singlet and triplet $\mathrm{H}_{2} \mathrm{CS}$ surfaces. Here, the thioformyl radical $\mathrm{HCS}\left(\mathrm{X}^{2} \mathrm{~A}^{\prime}\right)$ is the dominant reaction product on the triplet manifold, whereas $\mathrm{CS}\left(\mathrm{X}^{1} \Sigma^{+}\right)$can be formed on the singlet surface, too. Note that the thermodynamically less stable $\operatorname{HSC}\left(\mathrm{X}^{2} \mathrm{~A}^{\prime}\right)$ isomer is expected to be only a minor byproduct at the most. A second carbon atom increases considerably the complexity of the potential energy surfaces involved. Four reactions can access the $\mathrm{HC}_{2} \mathrm{~S}$ surface; the intermediates eject atomic hydrogen; the astronomically detected $\mathrm{C}_{2} \mathrm{~S}\left(\mathrm{X}^{3} \Sigma^{-}\right)$molecule can 


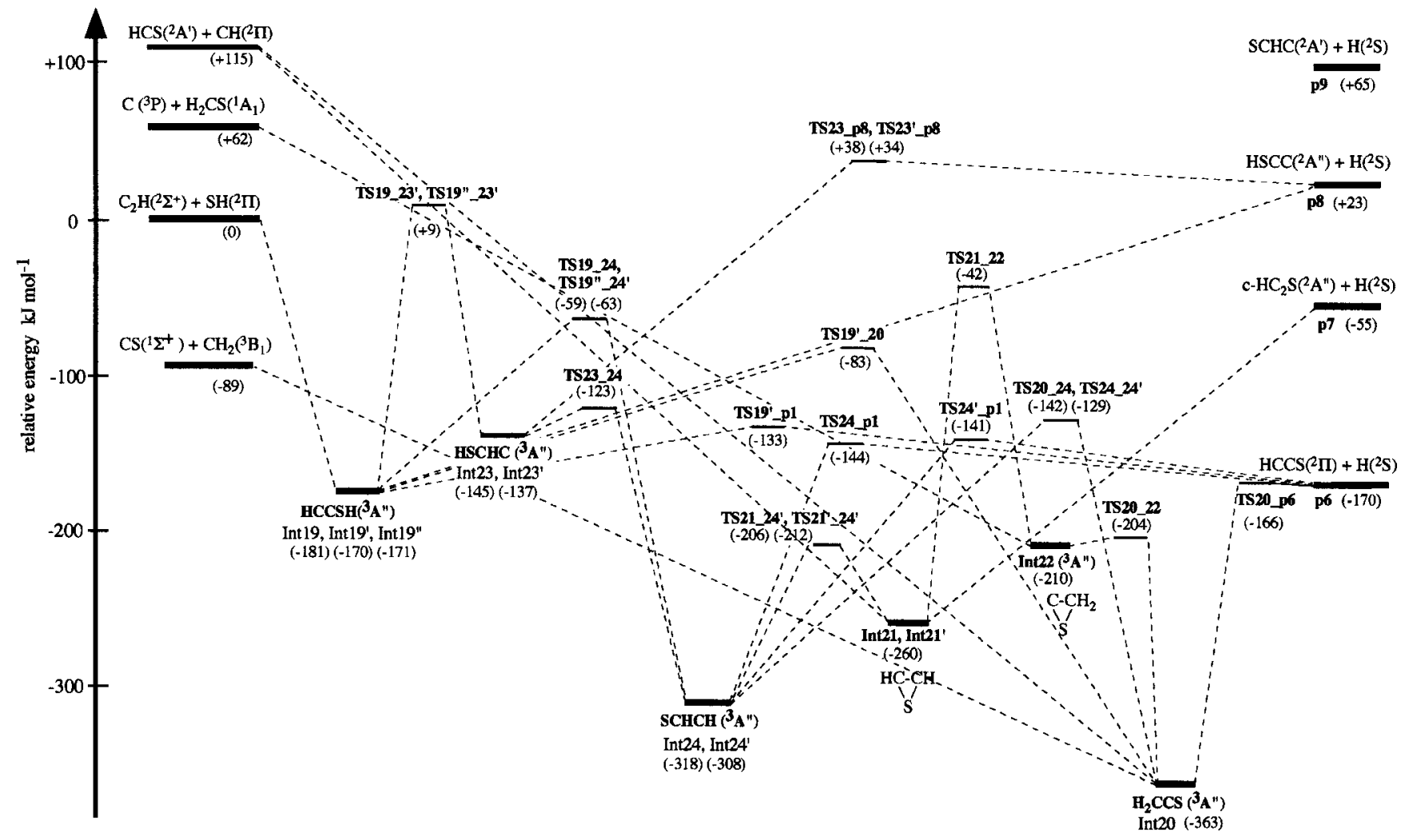

Fig. 14. Schematic representation of the triplet $\mathrm{H}_{2} \mathrm{C}_{2} \mathrm{~S}$ potential energy surface. "Int" indicates an intermediate, "TS" a transition state, and "p" the products.

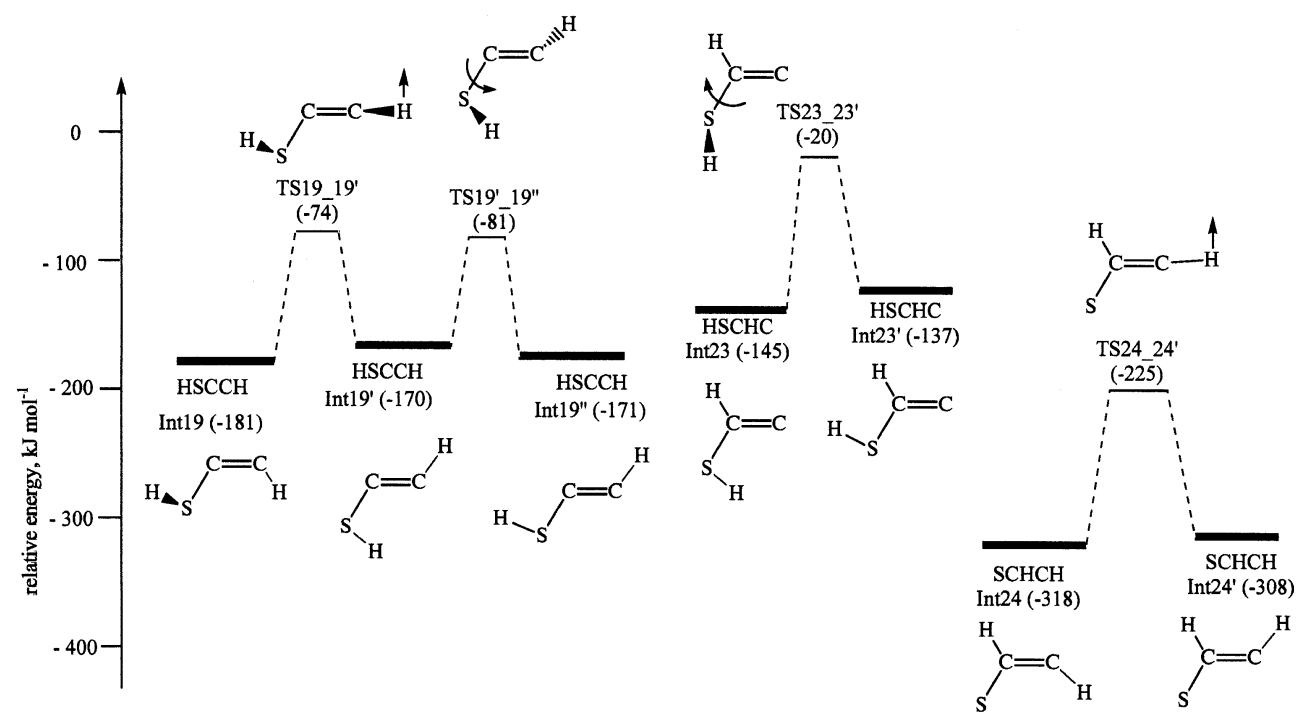

Fig. 15. Schematic representation of the isomerization of Int19, Int23, and Int24. "Int" indicates an intermediate and "TS" a transition state. The relative energies of the transition states are obtained with the B3LYP method.

be formed in three systems; the calculations reveal also that the hitherto unobserved cyclic isomer $\mathrm{c}_{-} \mathrm{C}_{2} \mathrm{~S}\left(\mathrm{X}^{1} \mathrm{~A}_{1}\right)$ might be also a significant product. Electronically excited $\mathrm{C}_{2} \mathrm{~S}\left(a^{1} \Delta\right)-$ if it is formed in molecular clouds - is expected to phosphorescence to the triplet surface; the $a^{1} \Delta \rightarrow \mathrm{X}^{3} \Sigma^{-}$transition is expected to occur around $2.097 \mu \mathrm{m}\left(4768 \mathrm{~cm}^{-1}\right)$ in the infrared regime. Five systems have been tackled theoretically to explore the triplet and singlet $\mathrm{H}_{2} \mathrm{C}_{2} \mathrm{~S}$ surfaces; these intermediates decompose via atomic hydrogen loss synthesizing predominantly the hitherto unobserved thioketenyl isomer $\operatorname{HCCS}\left(\mathrm{X}^{2} \Pi\right)$; based on the energetics, the three remaining isomers are expected to be of minor importance. Similar to $\mathrm{H}_{2} \mathrm{CS}$ intermediates, singlet $\mathrm{H}_{2} \mathrm{C}_{2} \mathrm{~S}$ structures can also release molecular hydrogen giving c- $\mathrm{C}_{2} \mathrm{~S}\left(\mathrm{X}^{1} \mathrm{~A}_{1}\right)$ and $/ \operatorname{orC}_{2} \mathrm{~S}\left(a^{1} \Delta\right)$.

These considerations help us to "design" future searches for hitherto unobserved $\operatorname{HCS}\left(X^{2} A^{\prime}\right)$ and $\operatorname{HCCS}\left(X^{2} \Pi\right)$ molecules in dark clouds. Since each isomer has a significant dipole moment of 1.23 Debye and 1.29 Debye, respectively, a search for their 

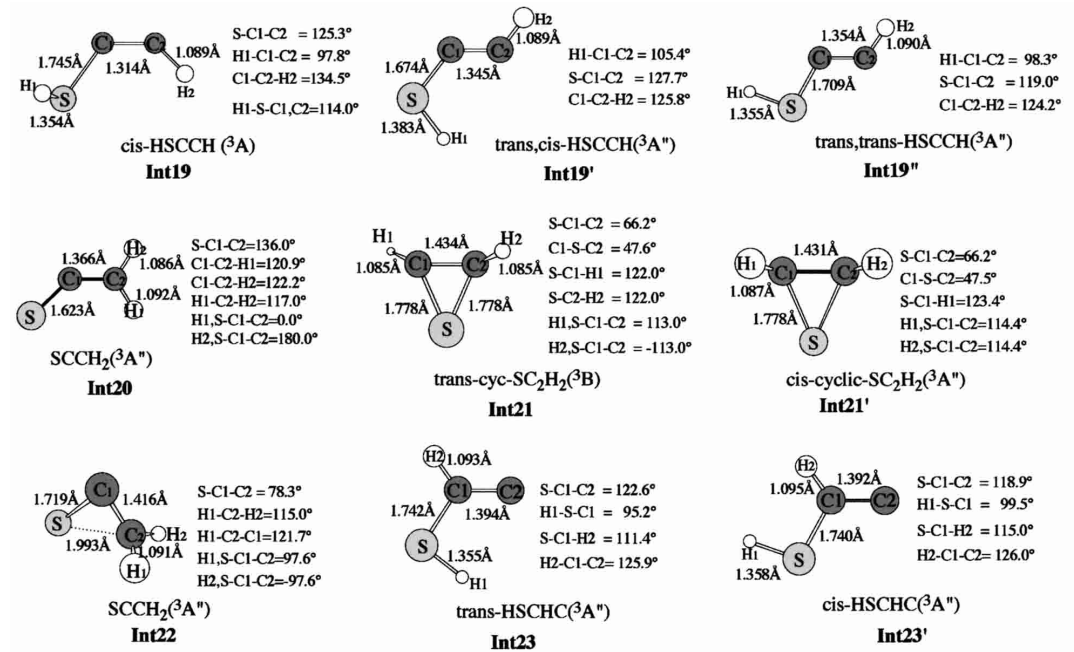

Int21'
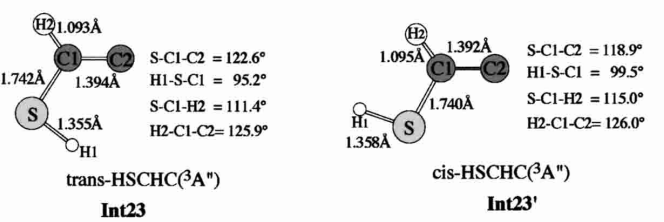$$
\text { Int23 }
$$$$
\text { Int23' }
$$

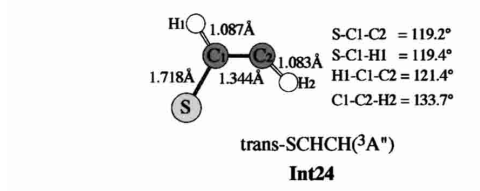

$$
\begin{aligned}
& \mathrm{S}-\mathrm{Cl}-\mathrm{C} 2=119.2^{\circ} \\
& \mathrm{S}-\mathrm{Cl}-\mathrm{H1}=11.4^{\circ} \\
& \mathrm{H} 1-\mathrm{Cl}-\mathrm{C} 2=124^{\circ} \\
& \mathrm{Cl}-\mathrm{C} 2-\mathrm{H} 2=133.7^{\circ}
\end{aligned}
$$

$$
\begin{aligned}
& \mathrm{S}-\mathrm{Cl}-\mathrm{H} 1=118.2^{\circ} \\
& \mathrm{S}-\mathrm{Cl}-\mathrm{C} 2=121.9^{\circ} \\
& \mathrm{Cl}-\mathrm{C} 2-\mathrm{H}_{2}=137.7^{\circ} \\
& \mathrm{H}, \mathrm{Cl}-\mathrm{C} 2-\mathrm{H}_{2}=0.0^{\circ} \\
& \mathrm{S}, \mathrm{Cl}-\mathrm{C} 2-\mathrm{H} 2=180.0^{\circ}
\end{aligned}
$$
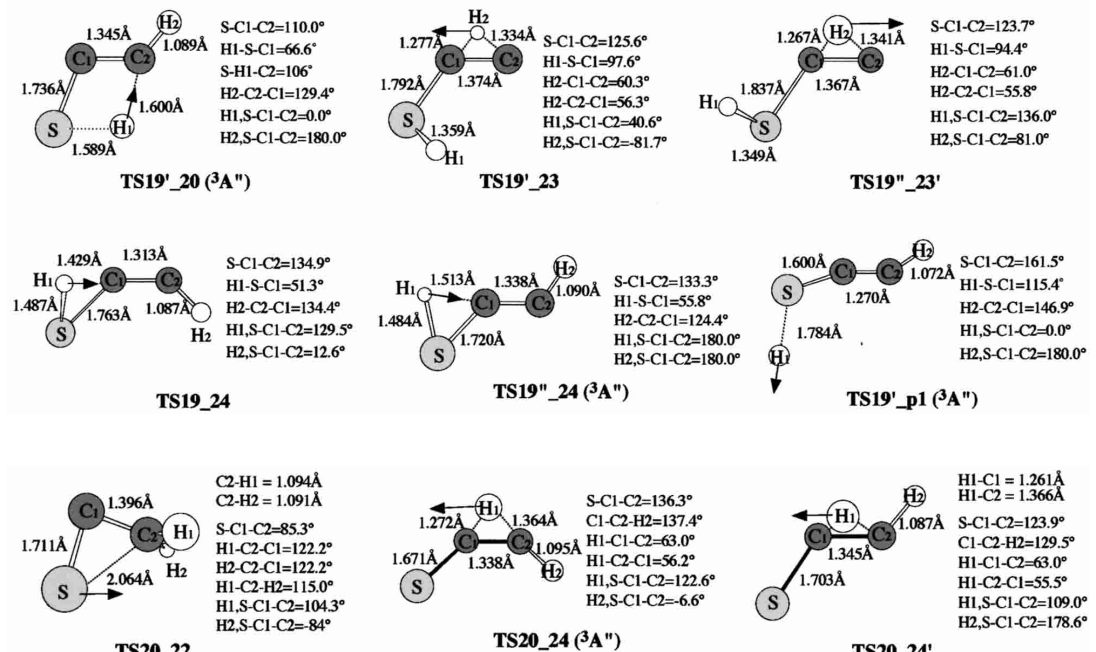

TS20_22

TS20_24 (3A")

TS20_24'
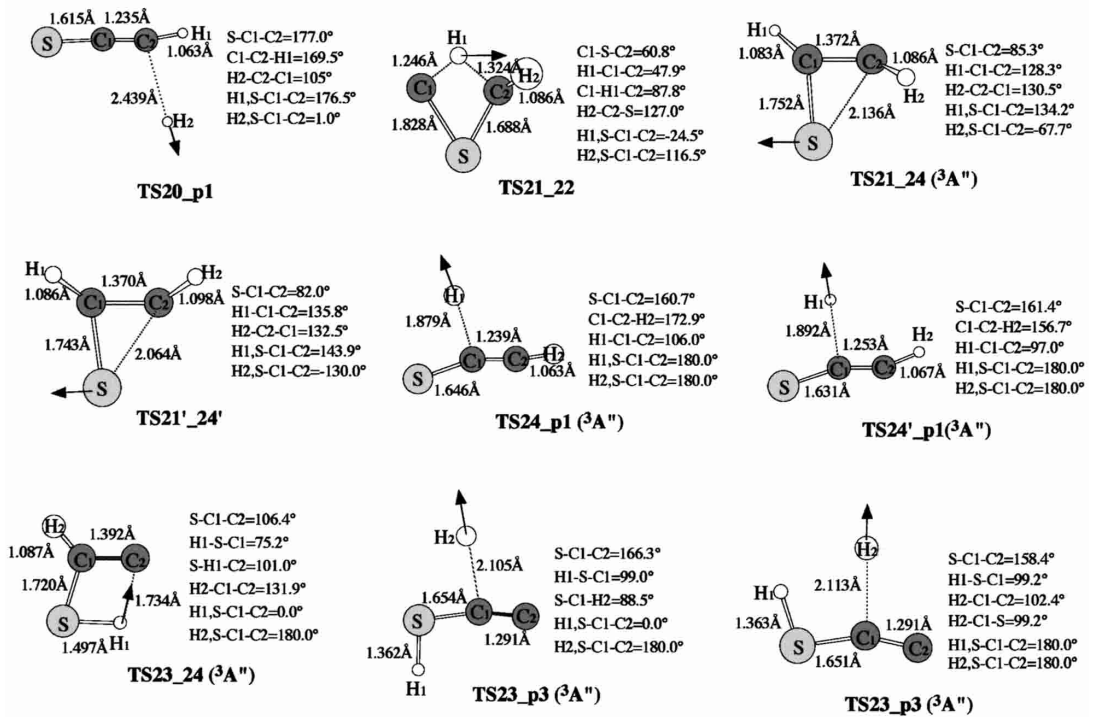

Fig. 16. Structures of intermediates and transition states of the triplet $\mathrm{H}_{2} \mathrm{C}_{2} \mathrm{~S}$ potential energy surface. Bond angles are given in degrees, bond distances in Angström. 


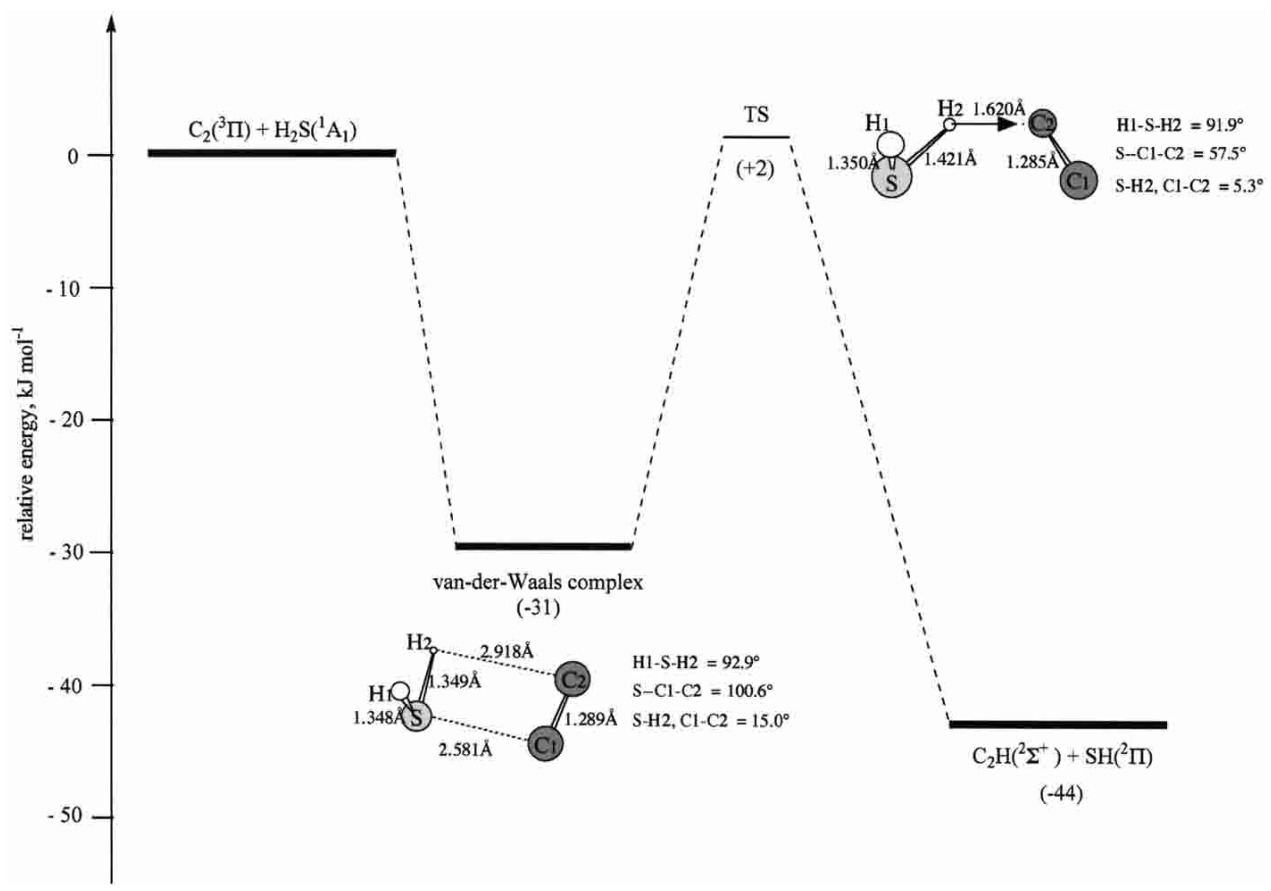

Fig. 17. Schematic representation on the reaction of triplet dicarbon with hydrogen sulfide.
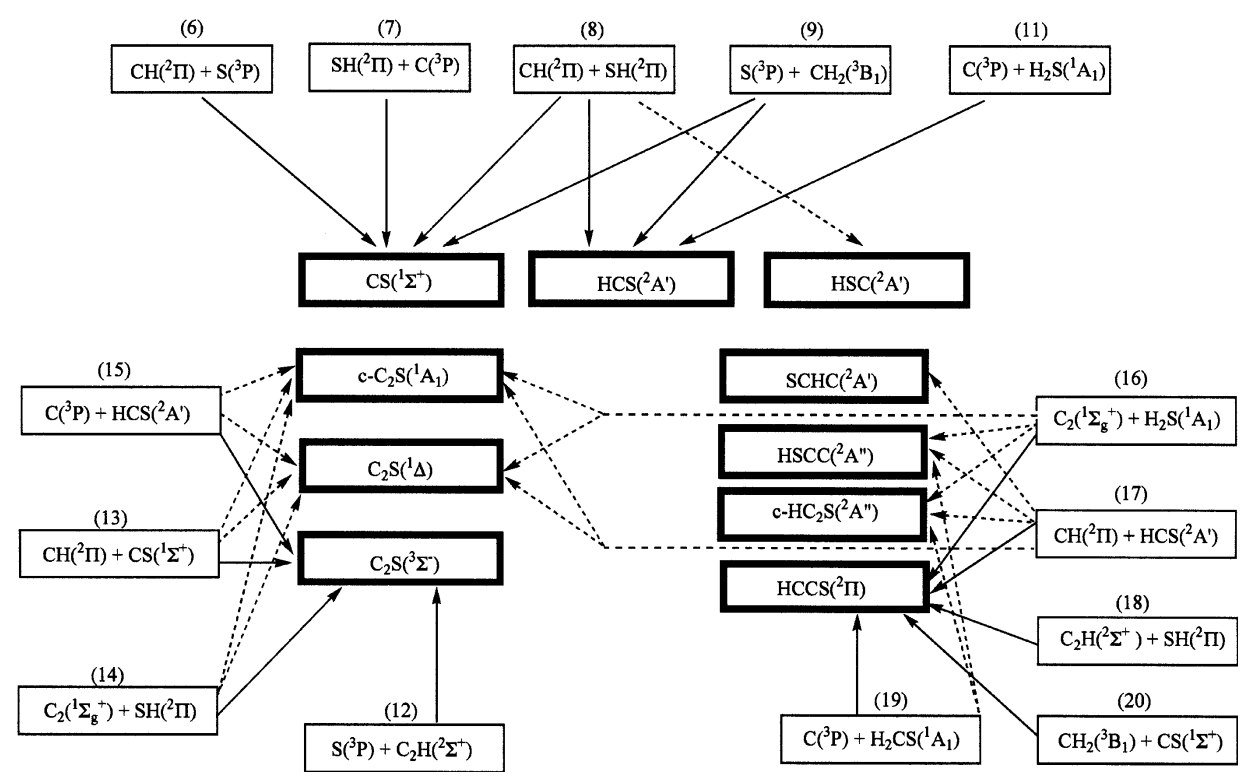

Fig. 18. Compilation of reactions leading to various $\mathrm{HC}_{n} \mathrm{~S}$ and $\mathrm{C}_{n} \mathrm{~S}$ isomers. Dashed and solid arrows indicate minor and major reaction pathways, respectively.

microwave transitions is advisable. The thioketenyl isomer is linear, and hence only B-type transitions can occur; this suggests that this isomer can be detected relatively easily. Table 1 compiles dipole moments, rotational constants, and infrared frequencies to assist an identification of important, but hitherto unobserved sulfur-bearing molecules. Preliminary studies of the crossed beam reaction of dicarbon with hydrogen sulfide suggest further the existence of two reaction channels, i.e. $\mathrm{HCCS}\left(\mathrm{X}^{2} \Pi\right)+\mathrm{H}$ and $\mathrm{C}_{2} \mathrm{~S}+\mathrm{H}_{2}$ (Kaiser et al. 2002); therefore, both molecules are expected to be present in OMC-1 and TMC-1 where $\mathrm{C}_{2} \mathrm{~S}$ is known to exist (Suzuki et al. 1992). We presented further compelling evidence that up to thirteen reactions can synthesize $\mathrm{C}_{n} \mathrm{~S}$ and $\mathrm{HC}_{n} \mathrm{~S}$ isomers $(n=1-2)$ in cold molecular clouds. To extract representative information on the chemical evolution of these extraterrestrial environments, it is important to include all, but not only selected reactions into future chemical models which investigate the sulfur chemistry in the interstellar medium. Obviously, this requires also the knowledge of temperature dependent rate constants together with branching ratios if multiple pathways are open. These studies are currently in progress.

Finally, we like to address briefly possible routes to form $\mathrm{C}_{3} \mathrm{~S}$ and $\mathrm{HC}_{3} \mathrm{~S}$ isomers via neutral - neutral reactions in cold molecular clouds. Previous crossed beam experiments showed 
Table 1. Dipole moments, rotational constants, and vibrational frequencies of the reaction intermediates and products calculated with the B3LYP/6-311G(d,p) method.

\begin{tabular}{|c|c|c|c|c|c|c|c|c|c|c|c|c|c|}
\hline \multirow[b]{2}{*}{ p1, Int1 HCS $\left({ }^{2} \mathrm{~A}^{\prime}\right)$} & \multirow{2}{*}{$\begin{array}{c}\text { dipole moment } \\
\text { (debye) }\end{array}$} & \multicolumn{3}{|c|}{$\begin{array}{l}\text { rotational constants } \\
(\mathrm{GHz})\end{array}$} & \multicolumn{4}{|c|}{$\begin{array}{l}\text { vibrational frequencies } \\
\qquad\left(\mathrm{cm}^{-1}\right)\end{array}$} & & & & & \\
\hline & & 894.6 & 20.2 & 19.8 & 853 & 1197 & 3096 & & & & & & \\
\hline $\mathrm{p} 2, \operatorname{Int} 2 \mathrm{HSC}\left({ }^{2} \mathrm{~A}^{\prime}\right)$ & 2.62 & 292.4 & 20.4 & 19.1 & 770 & 903 & 2339 & & & & & & \\
\hline Int 3 trans $-\mathrm{HSCH}\left({ }^{1} \mathrm{~A}^{\prime}\right)$ & 1.87 & 185.3 & 18.5 & 16.8 & 848 & 947 & 978 & 1179 & 2543 & 2956 & & & \\
\hline Int $3^{\prime}$ cis $-\mathrm{HSCH}\left({ }^{1} \mathrm{~A}^{\prime}\right)$ & 2.79 & 192.6 & 18.7 & 17.0 & 784 & 942 & 942 & 1114 & 2311 & 3032 & & & \\
\hline Int4 $\mathrm{H}_{2} \mathrm{CS}\left({ }^{1} \mathrm{~A}_{1}\right)$ & 1.80 & 294.0 & 17.6 & 16.6 & 1014 & 1032 & 1084 & 1500 & 3062 & 3148 & & & \\
\hline Int5 $\mathrm{H}_{2} \mathrm{SC}\left({ }^{1} \mathrm{~A}_{1}\right)$ & 3.94 & 230.9 & 19.4 & 17.9 & 245 & 612 & 976 & 1368 & 2084 & 2212 & & & \\
\hline Int6 $\mathrm{HSCH}\left({ }^{3} \mathrm{~A}\right)$ & 1.27 & 216.4 & 16.8 & 16.2 & 462 & 814 & 893 & 921 & 2509 & 3149 & & & \\
\hline Int7 $\mathrm{H}_{2} \mathrm{CS}\left({ }^{3} \mathrm{~A}^{\prime \prime}\right)$ & 0.71 & 279.7 & 16.1 & 15.3 & 293 & 774 & 843 & 1348 & 3113 & 3224 & & & \\
\hline Int8 $\mathrm{H}_{2} \mathrm{SC}\left({ }^{3} \mathrm{~A}^{\prime \prime}\right)$ & 4.24 & 154.3 & 15.0 & 14.8 & 383 & 523 & 652 & 1171 & 2403 & 2419 & & & \\
\hline p6, Int9 $\operatorname{HCCS}\left({ }^{2} \Pi\right)$ & 1.45 & 0 & 5.9 & 5.9 & 335 & 350 & 430 & 650 & 799 & 1919 & 3461 & & \\
\hline p7, Int10 c - $\mathrm{SC}_{2} \mathrm{H}\left({ }^{2} \mathrm{~A}^{\prime \prime}\right)$ & 2.60 & 39.0 & 11.7 & 9.0 & 435 & 708 & 790 & 1001 & 1512 & 3253 & & & \\
\hline p8, Int11 HSCC $\left({ }^{2} \mathrm{~A}^{\prime \prime}\right)$ & 4.48 & 288.6 & 6.1 & 6.0 & 165 & 217 & 744 & 985 & 1891 & 2552 & & & \\
\hline p9, Int12 SCHC $\left({ }^{2} A^{\prime}\right)$ & 1.94 & 121.5 & 6.3 & 6.0 & 228 & 680 & 683 & 842 & 1651 & 2983 & & & \\
\hline Int13 $\mathrm{H}_{2} \mathrm{SCC}\left({ }^{1} \mathrm{~A}^{\prime}\right)$ & 7.34 & 145.1 & 6.0 & 5.9 & 101 & 159 & 747 & 904 & 921 & 1209 & 1987 & 2383 & 2416 \\
\hline Int $14 \mathrm{HSCCH}\left({ }^{1} \mathrm{~A}^{\prime}\right)$ & 0.94 & 287.8 & 5.5 & 5.4 & 275 & 331 & 560 & 706 & 708 & 979 & 2161 & 2639 & 3478 \\
\hline $\operatorname{Int} 15 \mathrm{H}_{2} \mathrm{CCS}\left({ }^{1} \mathrm{~A}_{1}\right)$ & 1.20 & 289 & 5.6 & 5.5 & 360 & 416 & 721 & 857 & 928 & 1373 & 1826 & 3140 & 3219 \\
\hline Int16 c - $\mathrm{C}_{2} \mathrm{H}_{2} \mathrm{~S}\left({ }^{1} \mathrm{~A}_{1}\right)$ & 2.50 & 34.2 & 10.8 & 8.2 & 435 & 595 & 656 & 761 & 901 & 929 & 1757 & 3282 & 3339 \\
\hline $\operatorname{Int} 17 \mathrm{c}-\mathrm{H}_{2} \mathrm{CCS}\left({ }^{1} \mathrm{~A}^{\prime}\right)$ & 2.31 & 29.7 & 12.1 & 9.1 & 603 & 767 & 893 & 958 & 992 & 1141 & 1494 & 3086 & 3169 \\
\hline Int18 HSCHC $\left({ }^{1} \mathrm{~A}^{\prime}\right)$ & 3.00 & 36.2 & 9.6 & 8.0 & 324 & 535 & 659 & 680 & 957 & 996 & 1659 & 2579 & 3285 \\
\hline Int19 cis - HSCCH $\left({ }^{3} \mathrm{~A}\right)$ & 1.78 & 68.9 & 6.4 & 6.0 & 247 & 343 & 654 & 699 & 889 & 903 & 1630 & 2620 & 3116 \\
\hline Int19' trans, cis - HSCCH $\left({ }^{3} \mathrm{~A}^{\prime \prime}\right)$ & 1.20 & 87.5 & 6.4 & 5.9 & 302 & 404 & 706 & 717 & 823 & 981 & 1471 & 2345 & 3122 \\
\hline Int $19^{\prime \prime}$ trans, trans $-\mathrm{HSCCH}\left({ }^{3} \mathrm{~A}^{\prime \prime}\right)$ & 1.41 & 82.5 & 6.5 & 6.0 & 306 & 322 & 684 & 703 & 956 & 1009 & 1430 & 2609 & 3114 \\
\hline $\operatorname{Int} 20 \mathrm{SCCH} 2\left({ }^{3} \mathrm{~A}^{\prime \prime}\right)$ & 2.00 & 112.7 & 6.0 & 5.7 & 330 & 386 & 836 & 904 & 1058 & 1318 & 1478 & 3060 & 3175 \\
\hline Int $21 \mathrm{c}-\mathrm{SC}_{2} \mathrm{H}_{2}\left({ }^{3} \mathrm{~B}\right)$ & 0 & 28.9 & 12.5 & 9.0 & 674 & 684 & 805 & 901 & 946 & 1031 & 1249 & 3141 & 3146 \\
\hline Int $21^{\prime} \mathrm{c}-\mathrm{SC}_{2} \mathrm{H}_{2}\left({ }^{3} \mathrm{~A}^{\prime \prime}\right)$ & 1.43 & 28.9 & 12.5 & 9.0 & 666 & 689 & 813 & 842 & 935 & 1013 & 1267 & 3115 & 3130 \\
\hline Int22 $\mathrm{SCCH}_{2}\left({ }^{3} \mathrm{~A}^{\prime \prime}\right)$ & 1.80 & 33.5 & 10.6 & 8.5 & 404 & 697 & 834 & 1008 & 1053 & 1235 & 1488 & 3047 & 3120 \\
\hline Int23 trans - HSCHC $\left({ }^{3} \mathrm{~A}^{\prime \prime}\right)$ & 3.26 & 54.8 & 6.8 & 6.1 & 347 & 362 & 709 & 750 & 923 & 1173 & 1306 & 2614 & 3061 \\
\hline Int $23^{\prime}$ cis - HSCHC $\left({ }^{3} \mathrm{~A}^{\prime \prime}\right)$ & 4.64 & 56.0 & 6.8 & 6.1 & 323 & 325 & 695 & 738 & 898 & 1172 & 1297 & 2583 & 3036 \\
\hline Int24 trans - SCHCH $\left({ }^{3} \mathrm{~A}^{\prime \prime}\right)$ & 1.35 & 53.2 & 7.0 & 6.2 & 341 & 715 & 769 & 865 & 897 & 1258 & 1387 & 3132 & 3213 \\
\hline Int $24^{\prime}$ cis $-\mathrm{SCHCH}\left({ }^{3} \mathrm{~A}^{\prime \prime}\right)$ & 2.56 & 71.2 & 6.5 & 5.9 & 314 & 577 & 700 & 860 & 891 & 1243 & 1400 & 3045 & 3225 \\
\hline p3 $\mathrm{C}_{2} \mathrm{~S}\left(\mathrm{X}^{3} \Sigma^{-}\right)$ & 2.88 & 0 & 6.4 & 6.4 & 275 & 275 & 859 & 1721 & & & & & \\
\hline $\mathrm{p} 4 \mathrm{C}_{2} \mathrm{~S}\left(a^{1} \Delta\right)$ & 2.64 & 0 & 6.4 & 6.4 & 203 & 341 & 852 & 1742 & & & & & \\
\hline p5 c $-\mathrm{C}_{2} \mathrm{~S}\left(\mathrm{~A}^{1} \mathrm{~A}_{1}\right)$ & 2.32 & 40.8 & 14.5 & 10.7 & 719 & 747 & 1184 & & & & & & \\
\hline
\end{tabular}

that bimolecular reactions of atomic carbon $\mathrm{C}\left({ }^{3} \mathrm{P}_{\mathrm{j}}\right)$ and dicarbon molecules $\mathrm{C}_{2}\left(\mathrm{X}^{1} \Sigma_{\mathrm{g}}^{+}\right)$with hydrogen sulfide can indeed form $\mathrm{HCS}\left(\mathrm{X}^{2} \mathrm{~A}^{\prime}\right)+\mathrm{H}\left({ }^{2} \mathrm{~S}_{1 / 2}\right)$ and $\mathrm{HCCS}\left(\mathrm{X}^{2} \Pi\right)+\mathrm{H}\left({ }^{2} \mathrm{~S}_{1 / 2}\right)$ (Kaiser et al. 1999; Kaiser et al. 2002) via a $C / C_{2}$ versus atomic hydrogen exchange pathway:

$\mathrm{C}_{n}+\mathrm{H}_{2} \mathrm{~S} \rightarrow \mathrm{HC}_{n} \mathrm{~S}+\mathrm{H}\left({ }^{2} \mathrm{~S}_{1 / 2}\right)$.

Based on this versatile reaction scheme, we investigated also the reaction of tricarbon $\mathrm{C}_{3}\left(\mathrm{X}^{1} \Sigma_{\mathrm{g}}^{+}\right)$with hydrogen sulfide in a crossed beam setup (Kaiser 2002). Although two of three reaction pathways (22)-(24) are exoergic and hence energetically open, no reactive scattering signal for the CCCS molecule was observed.

$$
\begin{aligned}
& \mathrm{C}_{3}\left(\mathrm{X}^{1} \Sigma_{\mathrm{g}}^{+}\right)+\mathrm{H}_{2} \mathrm{~S} \rightarrow \mathrm{HCCCS}+\mathrm{H}\left({ }^{2} \mathrm{~S}_{1 / 2}\right) \\
& \Delta_{\mathrm{R}} \mathrm{G}(0 \mathrm{~K})=-101 \mathrm{kJmol}^{-1} \\
& \rightarrow \mathrm{HSCCC}+\mathrm{H}\left({ }^{2} \mathrm{~S}_{1 / 2}\right) \\
& \Delta_{\mathrm{R}} \mathrm{G}(0 \mathrm{~K})=+112 \mathrm{kJmol}^{-1} \\
& \rightarrow \mathrm{CCCS}+\mathrm{H}_{2}\left(\mathrm{X}^{1} \Sigma_{\mathrm{g}}^{+}\right) \\
& \Delta_{\mathrm{R}} \mathrm{G}(0 \mathrm{~K})=-227 \mathrm{kJmol}^{-1} .
\end{aligned}
$$

Our electronic structure calculations reveal that the potential between the two closed shell species tricarbon and hydrogen sulfide is repulsive; an $\mathrm{H}_{2} \mathrm{SCCC}$ structure in analogy to Int13 is not bound. Preliminary calculations suggest that the reaction of $\mathrm{C}_{3}\left(\mathrm{X}^{1} \Sigma_{\mathrm{g}}^{+}\right)$with $\mathrm{H}_{2} \mathrm{~S}$ follows rather an endoergic hydrogen abstraction $\left(+43 \mathrm{kJmol}^{-1}\right)$ and might involve a van-der-Waals complex which is stabilized by $2 \mathrm{kJmol}^{-1}$ with respect to the reactants. Therefore, we must conclude that bimolecular encounters between tricarbon and hydrogen sulfide do not form $\mathrm{C}_{3} \mathrm{~S}$ or $\mathrm{HC}_{3} \mathrm{~S}$ isomers in cold molecular clouds. However, the reaction of the dicarbon molecule $\mathrm{C}_{2}\left(\mathrm{X}^{1} \Sigma_{\mathrm{g}}^{+}\right)$with ubiquitous interstellar thioformaldehyde $\left(\mathrm{H}_{2} \mathrm{CS}\right)$ might form these elusive isomers in strongly exoergic reactions:

$$
\begin{aligned}
\mathrm{C}_{2}\left(\mathrm{X}^{1} \Sigma_{\mathrm{g}}^{+}\right)+\mathrm{H}_{2} \mathrm{CS}\left(\mathrm{X}^{1} \mathrm{~A}_{1}\right) \rightarrow & \mathrm{HCCCS}+\mathrm{H}\left({ }^{2} \mathrm{~S}_{1 / 2}\right) \\
& \Delta_{\mathrm{R}} \mathrm{G}(0 \mathrm{~K})=-257 \mathrm{kJmol}^{-1} \\
\rightarrow & \mathrm{CCCS}+\mathrm{H}_{2}\left(\mathrm{X}^{1} \Sigma_{\mathrm{g}}^{+}\right) \\
& \Delta_{\mathrm{R}} \mathrm{G}(0 \mathrm{~K})=-383 \mathrm{kJmol}^{-1}
\end{aligned}
$$


Previous studies of reactions of dicarbon with unsaturated hydrocarbons acetylene, ethylene, and methylacetylene (Kaiser et al. 2002; Kaiser 2002) depict no entrance barrier; if this concept of a barrier less reaction pathway of dicarbon with thioformaldehyde can be also verified, reactions (25) and (26) present compelling candidates to form $\mathrm{C}_{3} \mathrm{~S}$ or $\mathrm{HC}_{3} \mathrm{~S}$ isomers in the interstellar medium. These pathways are currently under investigation.

Acknowledgements. This research was supported by the Grantsin-Aid for Scientific Research on Priority Areas from the ministry of Education, Science, and Culture, Japan (Y.O.). Most of the ab initio calculations were carried out at the computer center of the Institute for Molecular Science, Japan. RIK acknowledges support from The University of York, UK. This work was performed within the International Astrophysics Network (http://www . chem. hawaii.edu/Bil301/welcome.html/).

\section{References}

Aschi, M., \& Largo, A. 2001, Chem. Phys., 265, 251

Becke, A. D. 1992, J. Chem. Phys., 97, 9173

Bakes, E. L. O. 1997, The astrochemical evolution of the interstellar medium (Twin Press, Vledder)

Chernicharo, J., Guelin, M., Hein, H., \& Kahane, C. 1987, A\&A, 181, L9

Combi, M. R., \& Fink, U. 1997, ApJ, 484, 879

Dunning, T. H. 1989, J. Chem. Phys., 90, 1007

Flores, J. R., \& Gomez, F. J. 2001, J. Phys. Chem. A, 105, 10384

Flores, J. R., Estévez, C. M., Carballeira, L., \& Pérez Juste, I. 2001, J. Phys. Chem. A, 105, 4716

Frisch, M. J., et al. GAUSSIAN 98, Revision A.9, Gaussian, Inc., Pittsburgh, Pennsylvania, 1998

Galland, N., Caralp, F., Rayez, M.-T., et al. 2001, J. Phys. Chem. A, 105,9893
Gordon, V. D., McCarthy, M. C., Apponi, A. J., \& Thaddeus, P. 2001, ApJS, 134, 311

Gredel, R. 1999, A\&A, 351, 657

Gredel, R., Black, J. H., \& Yan, M. 2001, A\&A, 375, 553

Hirahara, Y., Suzuki, H., Yamamoto, S., et al. 1992, ApJ, 394, 539

Kaiser, R. I. 2002, Chem. Rev., 102, 1309

Kaiser, R. I., \& Mebel, A. M. 2002, Int. Rev. Phys. Chem., 21, 307

Kaiser, R. I., Yamada, M., \& Osamura, Y. 2002, J. Phys. Chem. A, 106,4825

Kaiser, R. I., Ochsenfeld, C., Head-Gordon, M., \& Lee, Y. T. 1999, J. Chem. Phys., 110, 2391

Krishnan, R., Frisch, M., \& Pople, J. A. 1988, J. Chem. Phys., 72, 4244

Lee, C., Yang, W., \& Parr, R. G. 1988, Phys. Rev. B, 37, 785

Markwick, A. J., Millar, T. J., \& Charnley, S. B. 2000, ApJ, 535, 256

Millar, T. J., \& Herbst, E. 1990, A\&A, 231, 466

Millar, T. J., Flores, J. R., \& Marwick, A. J. 2001, MNRAS, 327, 1173

Minh, Y. C., \& van Dishoeck, E. F. 2000, From Molecular Clouds to Planetary Systems, IAU Symp., 197

Ochsenfeld, C., Kaiser, R. I., Lee, Y. T., \& Head-Gordon, M. 1999, J. Chem. Phys., 110, 9982

Petrie, S. 1996, MNRAS, 281, 666

Redondo, P., Calleja, E., Barrientis, C., \& Largo, A. 1999, J. Phys. Chem. A, 103, 9125

Scappini, F., \& Codella, C. 1996, MNRAS, 282, 587

Suzuki, H., Yamamoto, S., Ohishi, M., et al. 1992, ApJ, 392, 551

Tatematsu, K., Jaffe, D. T., Plume, R., et al. 1999, ApJ, 526, 295

Thaddeus, P., Kutner, M. L., Penzias, A. A., et al. 1972, ApJ, 176, L73

Van der Keen, W. E. C. J., Huggins, P. J., \& Matthews, H. E. 1998, ApJ, 505, 749

Van Dishoek, E. F., \& Black, J. H. 1989, ApJ, 340, 273

Velusamy, T., Kuiper, T. B. H., \& Langer, W. D. 1995, ApJ, 451, L75

Wootten, A. 2002, http://www.cv.nrao.edu/ awootten/ allmols.html

Yamamoto, S., Saito, S., Kawaguchi, K., et al. 1990, ApJ, 361, 318

Young, K. 1997, ApJ, 488, L1570 